\title{
Characterization of deactivated and regenerated zeolite ZSM-5-based catalyst extrudates used in catalytic pyrolysis of biomass
}

\author{
E. Heracleous ${ }^{\mathrm{a}, \mathrm{b}, *}$, E. Pachatouridou ${ }^{\mathrm{a}}$, A.M. Hernández-Giménez ${ }^{\mathrm{c}}$, H. Hernando $^{\mathrm{d}, \mathrm{e}}$, T. Fakin ${ }^{\mathrm{f}}$, A.L. Paioni ${ }^{\mathrm{g}}$, \\ M. Baldus ${ }^{g}$, D.P. Serrano ${ }^{\text {d,e }}$, P.C.A. Bruijnincx ${ }^{\text {c,h }}$, B.M. Weckhuysen ${ }^{c}$, A.A. Lappas ${ }^{\text {a }}$ \\ ${ }^{a}$ Chemical Process E Energy Resources Institute (CPERI), Centre for Research and Technology Hellas (CERTH), 6th km Charilaou - Thermi Road, P.O. Box 361, 57001 \\ Thessaloniki, Greece \\ ${ }^{\mathrm{b}}$ School of Science Er Technology, International Hellenic University (IHU), 14th km Thessaloniki - Moudania, 57001 Thessaloniki, Greece \\ ${ }^{\mathrm{c}}$ Inorganic Chemistry and Catalysis, Debye Institute for Nanomaterials Science, Utrecht University, Universiteitsweg 99,3584 CG Utrecht, the Netherlands \\ ${ }^{\mathrm{d}}$ Thermochemical Processes Unit, IMDEA Energy Institute, 28935, Móstoles, Madrid, Spain \\ e Chemical and Environmental Engineering Group, ESCET, Rey Juan Carlos University, 28933, Móstoles, Madrid, Spain \\ ${ }^{f}$ SILKEM, d.o.o., Tovarniška cesta 10, SI - 2325 Kidričevo, Slovenia \\ ${ }^{\mathrm{g}}$ NMR Spectroscopy, Bijvoet Center for Biomolecular Research, Utrecht University, Padualaan 12, 3584 CH Utrecht, the Netherlands \\ ${ }^{\mathrm{h}}$ Organic Chemistry and Catalysis, Debye Institute for Nanomaterials Science, Utrecht University, Universiteitsweg 99 , 3584 CG Utrecht, the Netherlands
}

\section{A R T I C L E I N F O}

\section{Article history:}

Received 17 June 2019

Revised 16 September 2019

Accepted 12 October 2019

Available online 15 November 2019

\section{Keywords:}

Catalytic pyrolysis

Biomass

Zeolite ZSM-5

Catalyst deactivation

Catalyst extrudates

\begin{abstract}
A B S T R A C T
A major issue in the catalytic fast pyrolysis (CFP) of biomass is the rapid deactivation of the typically employed zeolite-based catalysts. Detailed understanding of the deactivation pathways and the type and location of coke deposits are essential for the further development of improved or new catalyst materials, including appropriate regeneration protocols. Such deactivation and regeneration studies focus almost invariably on small-scale CFP reactor units employing catalyst materials in powder form. In this study, we report the in-depth characterization of deactivated and regenerated $\mathrm{ZrO}_{2}$-promoted zeolite ZSM-5 catalyst extrudates after ex-situ CFP tests carried out in a bench scale reactor. The findings support that coking is the main reason for catalyst deactivation, i.e. for the observed decreased activity in cracking and deoxygenation. Post-mortem characterization by confocal fluorescence microscopy reveals an eggshell spatial distribution of the coke deposits within the catalyst extrudates. These deposits are heavily poly-aromatic in nature. The majority of the coke build-up occurs in the first $20 \mathrm{~min}$ of the reaction and is formed on the strong Brønsted acid sites, which promote deep deoxygenation and cracking. With increasing time-on-stream, the coke deposition slows down, occurring now mainly on the external surface of the zeolite to generate a softer, i.e. more hydrogen-rich, coke on the $\mathrm{ZrO}_{2}$ domains. The catalyst is readily regenerated via thermal oxidation in air, with optimal regeneration at $500{ }^{\circ} \mathrm{C}$. This temperature removes all coke deposits, with no detrimental effect on the catalyst's structural, textural and acid (type and strength) properties.
\end{abstract}

(c) 2019 Elsevier Inc. All rights reserved.

\section{Introduction}

Catalytic fast pyrolysis (CFP) of biomass is considered as one of the most promising thermochemical routes for the production of 2nd generation biofuels with satisfactory quality at high liquid yields [1]. The process can be operated in two main configurations: in-situ, where the catalyst is placed in the pyrolysis reactor and acts also as the heating medium, and ex-situ, where the catalytic

* Corresponding author at: Chemical Process \& Energy Resources Institute (CPERI), Centre for Research and Technology Hellas (CERTH), 6th km Charilaou Thermi Road, P.O. Box 361, 57001 Thessaloniki, Greece.

E-mail address: eheracle@cperi.certh.gr (E. Heracleous). upgrading of the thermally-generated biomass pyrolysis vapors takes place in a second reactor closely coupled to the pyrolyzer. The latter approach has received significant attention in the last years due to the possibility of individually optimizing the two steps [2]. Ex-situ CFP is also an effective way to avoid the poisoning of the catalyst from biomass-derived metals, as the metals are typically retained in the char produced thermally in the first reactor [3]. A plethora of catalytic materials, such as zeolites, mesoporous materials with uniform pore size distribution (i.e., MCM-41, MSU, and SBA-15), microporous/mesoporous hybrid materials optionally doped with noble and transition metals, and base catalysts have been investigated as candidates for biomass pyrolysis, with zeolite ZSM-5 being the most widely studied material [4]. 
One of the main drawbacks of using zeolites as catalysts in biomass CFP is their fast deactivation. During the course of the reaction, the catalysts rapidly deactivate due to pore blockage, active site poisoning, mineral deposition, dealumination and mechanical instability and require appropriate regeneration $[5,6]$. To gain detailed insight into the operational deactivation phenomena, extensive characterization of the nature and location of the coke deposits and the chemical changes that occur in the catalyst material is required. Such knowledge is essential to guide the design of the next generation catalyst materials and the related conversion process, such as the type of the catalytic reactor (fixed vs. fluidized bed) and the size and operating conditions of the regenerator, parameters that significantly affect the overall economics of the catalytic process. Although this topic has been extensively studied in the case of catalysts used in petrochemical refining [7-10], the deactivation/regeneration of biomass pyrolysis catalysts has received much less attention and the mechanism of zeolite deactivation in biomass upgrading is not yet fully understood.

Vitolo et al. [11] studied the recyclability of a zeolite ZSM-5 catalyst in the upgrading of wood-derived pyrolysis oil in a fixed bed reactor at $450^{\circ} \mathrm{C}$. Repeated upgrading/regeneration cycles showed that the catalyst gradually deactivates after each cycle and loses its activity irreversibly after five such cycles. The loss of activity was mainly connected with the loss of strong acid sites, even at low regeneration temperature $\left(500{ }^{\circ} \mathrm{C}\right)$, due to local hot spots in the regeneration bed. Similar results were also obtained over a zeolite USY catalyst employed for the CFP of lignin [12]. Although regeneration restored porosity and acidity to a large extent, deactivation was not completely reversible because of structural changes in the catalyst during the regeneration process. In addition, Wan et al. [13] showed that the density of acid sites in zeolite ZSM-5 plays a critical role in catalyst stability, with lower Si/Al ratios leading to increased catalyst deactivation rates. Yung et al. [14] investigated the effect of regeneration temperature on the properties and activity of ZSM-5 $(\mathrm{Si} / \mathrm{Al}=15)$ in order to understand the effective conditions to regenerate zeolites in CFP. Oxidative treatment at high temperatures $\left(650\right.$ and $700{ }^{\circ} \mathrm{C}$ ) fully regenerated the catalyst, which maintained its catalytic performance over several reaction/regeneration cycles on a micro-scale reactor. Lower regeneration temperatures, i.e. $550{ }^{\circ} \mathrm{C}$ and $600{ }^{\circ} \mathrm{C}$, required longer regeneration times and in the case of regeneration at $500{ }^{\circ} \mathrm{C}$, the catalyst activity was not fully restored due to remaining coke species.

Characterization of the nature of the coke deposited on zeolite ZSM-5 [15] and Ni-modified zeolite ZSM-5 [16] during the upgrading of bio-oil, co-fed with methanol, to hydrocarbons showed the coke to be heterogeneous, depositing on both the external and internal zeolite surface. Most of the coke was found to be deposited outside the zeolite crystals and consisted of oxygenates and oxygenated-aromatics, formed from the polymerization of ligninderived products in bio-oil. Mukarakate et al. [17], who investigated the conversion of pine pyrolysis vapors over fixed beds of a zeolite ZSM-5 catalyst as a function of catalyst deactivation, also concluded that coking initially occurs on the outside of the catalyst, leaving the micropores largely intact. It was also shown that the amount of oxygen in the upgraded reaction products was related to the level of deactivation of the ZSM-5 catalyst.

All of the above highlight the importance of understanding the type and location of coke deposits in biomass pyrolysis catalysts to employ appropriate regeneration protocols that can recover the initial catalyst properties and activity. Most of the cited studies, however, were conducted in small-scale pyrolyzers or microreactors using small amounts of catalysts in their powdered form. Commercial operation would require shaped catalyst bodies, such as extrudates and tablets, for which the modes of catalyst deactivation can differ substantially. Comparison of tablet-shaped and ring-shaped $\mathrm{Pt} / \mathrm{CeO}_{2} / \alpha-\mathrm{Al}_{2} \mathrm{O}_{3}$ catalyst materials in natural gas steam reforming, for example, showed the latter to perform significantly better both in initial activity and deactivation resistance [18]. Bobadilla et al. [19] investigated the influence of the shape of Ni catalysts in glycerol steam reforming. Although the initial activity was the same for all samples, powders and egg-shell pellets were found to deactivate much faster than monoliths. These variations were attributed to the different degrees of coking, with the monolith exhibiting much lower coke formation and pore blockage than the other two solids.

Not only the shape, but also the binder element used to mold the catalyst system into shape can significantly influence catalyst properties and hence performance, including stability. Ibáñez et al. [20] reported the transformation of chloromethane into olefins by technical catalysts consisting of zeolite ZSM-5 extruded with bentonite and $\mathrm{Al}_{2} \mathrm{O}_{3}$ as binders. Regeneration in air at $550{ }^{\circ} \mathrm{C}$ showed that deactivation by coke is reversible but only if a maximum reaction temperature of $400{ }^{\circ} \mathrm{C}$ is employed; for reactions carried out at higher temperature additional dealumination by formed $\mathrm{HCl}$ leads to irreversible deactivation. Evaluation of HZSM-5 $(\mathrm{Si} / \mathrm{Al}=15)$ catalysts with different binders (alumina, silica, and clay) in the upgrading of pine pyrolysis vapors on a micro-scale analytical Py-GCMS/FID [21] showed that the catalyst with alumina gives higher coke yields and exhibits faster deactivation than clay and silica-containing catalysts. This was attributed to the additional acidity provided by alumina. Hutchings et al. [22] investigated the effect of temperature, time and atmosphere on the regeneration of extruded zeolite $\mathrm{H}-\mathrm{Y}$ catalysts and found the application of oxygen at temperatures of $450-500{ }^{\circ} \mathrm{C}$ to be most efficient when considering the extent of carbon removal. Milder regeneration conditions, however, avoided irreversible dealumination by the gases formed upon burning and were preferred over the harsh regeneration conditions that readily remove coke, but inevitably damage the catalyst structure, ultimately extending the lifetime most. In a recent work, Whiting et al. investigated the deactivation of zeolite ZSM-5 in combination with a clay mineral as binder material, namely kaolinite or bentonite, for the methanol-to-hydrocarbons reaction [23]. Using confocal fluorescence microscopy in combination with fluorescent dyes of different molecular sizes, it was possible to spatially map the gradual formation of different types (and growing molecular size) of coke (precursor) deposits within the zeolite-clay catalyst extrudates with increasing time-on-stream. A relationship between decreasing pore accessibility and increasing catalyst deactivation rate was reported.

In this work, we investigate the deactivation phenomena in the ex-situ catalytic fast pyrolysis (CFP) of wood-based biomass at bench scale over shaped $\mathrm{ZrO}_{2}$-promoted nanocrystalline zeolite ZSM-5 catalyst extrudates agglomerated with attapulgite as the clay binder material. We have previously shown the remarkable performance of $\mathrm{ZrO}_{2} / \mathrm{n}-\mathrm{ZSM}-5$ in biomass catalytic pyrolysis as a result of a balanced combination of accessibility for bulky molecules (due to its nanocrystalline nature) and acidic properties [24]. Modification of the zeolite's acidity by incorporation of $\mathrm{ZrO}_{2}$ effectively decreases the extent of secondary reactions, such as severe cracking and coke formation, and promotes the conversion of the oligomers formed initially by lignocellulose pyrolysis. Agglomeration of $\mathrm{ZrO}_{2} / \mathrm{n}-\mathrm{ZSM}-5$ with attapulgite considerably enhances the bio-oil deoxygenation activity in comparison with the binder-free material, due to the good balance between acid and basic sites in the technical catalyst [25]. Here, deactivated $\mathrm{ZrO}_{2} / \mathrm{n}$-ZSM-5-ATP catalyst extrudates obtained from bench scale tests after different pyrolysis times are regenerated at three different temperatures. The fresh, used and regenerated catalyst materials are characterized extensively. Special attention is paid to the formation of coke deposits within deactivated samples, analyzed 
by both bulk thermochemical analyses and by post-mortem spatial examination with confocal fluorescence microscopy to assess both the origin of deactivation of tailored zeolite extrudates exposed to biomass pyrolysis vapor upgrading and the influence of the different regeneration protocols on the catalyst properties.

\section{Experimental}

\subsection{Catalyst materials and synthesis}

The catalyst material used for the study was a $10 \mathrm{wt} \% \mathrm{ZrO}_{2}$ promoted zeolite ZSM-5 catalyst (with a $\mathrm{Si} / \mathrm{Al}$ ratio of 45 ) agglomerated with $30 \mathrm{wt} \%$ attapulgite in an extrudate form. $\mathrm{ZrO}_{2}$ impregnation was carried out by diluting zirconyl (IV) nitrate hydrate (Acros, 99.5\%) in distilled water at $40{ }^{\circ} \mathrm{C}$ under continuous stirring. Once dissolved the zeolite ZSM-5 was added by doses, and the suspension was stirred at $60{ }^{\circ} \mathrm{C}$ for $12 \mathrm{~h}$. The viscous paste was subsequently transferred to a drying plate inside an oven, at $100^{\circ} \mathrm{C}$. Once dry, it was crushed, milled and homogenized. Calcination was carried at $450{ }^{\circ} \mathrm{C}$ for $3 \mathrm{~h}$ in air. The powder was then mixed with attapulgite and water was slowly added to perform the agglomeration. When the extrusion was completed, the catalyst extrudates were sieved and dried in a fluidized bed dryer. After drying, sieving was performed to remove any remaining fines. Finally, the catalyst extrudates, in the shape of cylinders with $3 \mathrm{~mm}$ diameter and 5$6 \mathrm{~mm}$ length, were dried in an oven for $3 \mathrm{~h}$ and calcined at $550{ }^{\circ} \mathrm{C}$ for $3 \mathrm{~h}$ in air.

\subsection{Bench scale catalytic pyrolysis of biomass}

The catalyst deactivation studies were carried out in a fully automated continuous biomass pyrolysis bench scale unit, shown schematically in Fig. S1. The unit consists of two reactors, a fluidized bed and a fixed bed reactor, connected in series. The first reactor is used to perform the thermal pyrolysis step of the process, while in the second reactor the catalytic upgrading of the biomass pyrolysis vapors takes place. The feedstock employed was a typical lignocellulosic biomass (oak) supplied by ENCE in Spain with the following properties: Moisture $8.6 \mathrm{wt} \%$; ash $0.6 \mathrm{wt} \%$ d.b.; C 49.6 wt\% d.b.; H 5.9 wt\% d.b.; O 43.9 wt\% d.b. by difference.

Biomass was introduced in the fluidized bed reactor through a screw feeder at a feed rate of $5 \mathrm{~g} / \mathrm{min}$. At the same time, $\mathrm{N}_{2}$ was inserted at the bottom of the reactor to achieve fluidization. The reactor was loaded with silica sand used as inert material and was heated by an external furnace at $550{ }^{\circ} \mathrm{C}$, with the temperature being controlled by suitable thermocouples. The pyrolysis vapors produced in the first reactor during the thermal pyrolysis were introduced into the second reactor, loaded with $25 \mathrm{~g}$ of the $\mathrm{ZrO}_{2} /$ n-ZSM-5-ATP catalyst extrudates. The upgrading reactor was heated by a different furnace up to $450{ }^{\circ} \mathrm{C}$ and the exit stream was directed to the product separation and collection section of the unit. In all tests, the liquid and gaseous products were separated, collected and measured.

The liquid product was collected in two separate vessels and was analyzed after mixing into a single sample. The water content of the bio-oil was determined by Karl-Fischer titration (ASTM D6304). Carbon and hydrogen were determined concurrently in a LECO-800 CHN analyzer, measured as $\mathrm{CO}_{2}$ and $\mathrm{H}_{2} \mathrm{O}$ by selective infrared cells (detectors). The oxygen content was calculated by difference. The organic phase of the bio-oil was analyzed by GCMS using an Agilent 7890A/5975C gas chromatograph-mass spectrometer system (Electron energy: $70 \mathrm{eV}$; Emission: $300 \mathrm{~V}$; Helium flow rate: $0.7 \mathrm{~cm}^{3} / \mathrm{min}$; Column: HP-5MS $(30 \mathrm{~m} \times 0.25 \mathrm{~mm}$ ID $\times 0.25 \mu \mathrm{m})$ ). Internal libraries were used for the identification of the compounds found in the bio-oil and their categorization into main functional groups. The analysis performed was semiquantitative and the results refer to the relative area of the peaks of the different compounds in the chromatograph. Gases were ana-

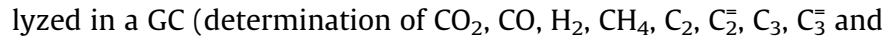
other light hydrocarbons up to $\mathrm{C}_{6}$ ), while solid products (char \& coke) were measured together during the regeneration stage, by replacing the nitrogen in the bed with air and increasing the bed temperature of both reactors up to $650^{\circ} \mathrm{C}$.

In order to investigate the deactivation of the catalyst, biomass pyrolysis tests with ex-situ upgrading were performed at two different run times, namely 20 and 40 min time-on-stream, at constant reaction conditions (WHSV $=12 \mathrm{~h}^{-1}$ and $\mathrm{P}=1 \mathrm{bar}$ ). Three repetitive experiments were conducted for each run time. The mass balance of the catalytic pyrolysis tests was better than $90 \%$. In the last test of each series, the catalyst material was not regenerated and the reactor was cooled under nitrogen to collect the deactivated catalyst extrudates. The fresh and deactivated samples from the two runs at 20 and 40 min are denoted as Fresh, Used20 and Used40, respectively.

\subsection{Catalyst regeneration}

The deactivated $\mathrm{ZrO}_{2} / \mathrm{n}$-ZSM-5-ATP catalyst extrudates after $20 \mathrm{~min}$ and $40 \mathrm{~min}$ time-on-stream in continuous biomass pyrolysis tests with ex-situ upgrading were regenerated at three different temperatures, $400{ }^{\circ} \mathrm{C}, 500^{\circ} \mathrm{C}$ and $600^{\circ} \mathrm{C}$, for $3 \mathrm{~h}$ (heating rate: $5^{\circ} \mathrm{C}$ / min), in a furnace with static air. The regenerated samples are denoted as RegX_T, where $\mathrm{X}$ is 20 or 40 (for pyrolysis time of $20 \mathrm{~min}$ and $40 \mathrm{~min}$, respectively) and $\mathrm{T}$ the regeneration temperature.

\subsection{Catalyst characterization}

Transmission Electron Microscopy (TEM) images of fresh, used and regenerated catalysts were taken on a Tecnai 20 (FEI, $200 \mathrm{kV}$ ) transmission electron microscope. Samples were deposited on $\mathrm{Cu}$ with $\mathrm{C}$ coating TEM grids, after grinding and suspending in ethanol. One representative TEM image, from an average of 10-16 pictures taken from random locations, is shown per sample, with additional TEM images included in the SI.

Surface areas of the samples were determined by $\mathrm{N}_{2}$ adsorption at $-196^{\circ} \mathrm{C}$, using the multipoint BET analysis method, with an Autosorb-1 Quantachrome flow apparatus. Prior to the measurements, the samples were dehydrated in vacuum at $450{ }^{\circ} \mathrm{C}$ overnight. The Brunauer-Emmet-Teller (BET) equation was used to calculate the apparent surface area $\left(\mathrm{S}_{\mathrm{BET}}\right)$, while the micropore volume $\left(\mathrm{V}_{\text {micro }}\right)$ and the external surface $\left(\mathrm{S}_{\text {ext }}\right)$ were calculated using the NLDFT model.

X-ray diffraction (XRD) measurements were performed using a SIEMENS D-500 diffractometer employing $\mathrm{CuK}_{1}$ radiation $(\lambda=0.15405 \mathrm{~nm})$ and operating at $40 \mathrm{kV}$ and $30 \mathrm{~mA}$. The XRD patterns were accumulated in the $2 \theta$ range of $5-80^{\circ}$ with a $0.02^{\circ}$ step size and a counting time of $2 \mathrm{~s}$ per step.

${ }^{27} \mathrm{Al}$ magic angle spinning solid-state nuclear magnetic resonance (MAS ssNMR) experiments were performed at $11.7 \mathrm{~T}$ on a Bruker Avance III spectrometer equipped with a $3.2 \mathrm{~mm}$ MAS probe. The sSNMR spectra were recorded at ambient temperature using $15 \mathrm{kHz}$ MAS. An RF field of $50 \mathrm{kHz}$ was used for the ${ }^{27} \mathrm{Al}$ $\pi / 12$ pulse followed by $26 \mathrm{~ms}$ acquisition. 10,240 scans were accumulated using an inter-scan delay of $1 \mathrm{~s}$. The ${ }^{27} \mathrm{Al}$ chemical shift was externally referenced to aluminum nitrate $\left(\mathrm{Al}\left(\mathrm{NO}_{3}\right)_{3}(\mathrm{aq})\right)$. The 1D spectra were processed using a line-broadening of $100 \mathrm{~Hz}$. A zero-quantum (ZQ) filtered multiple-quantum magic angle spinning (MQ-MAS) pulse-sequence was used to correlate the ${ }^{27} \mathrm{Al}$ isotropic chemical shift (F1) with the quadrupolar lineshape (F2). The excitation and conversion pulses were applied with 
an RF field of $62 \mathrm{kHz}$. For the selective pulse following the Z-filter delay, an RF field of $6.5 \mathrm{kHz}$ was used. The incrementation time for the indirect dimension was set to one rotation period and 36 increments were recorded. The direct acquisition time was set to $2.5 \mathrm{~ms}$ and 240 scans were accumulated using an inter-scan delay of $2 \mathrm{~s}$. MQ-MAS data were Fourier Transformed and sheared using the software of Bruker Topspin 3.5 and $250 \mathrm{~Hz}$ line-broadening was applied in both dimensions.

FT-IR spectra after pyridine adsorption were collected using a Nicolet 5700 FT-IR spectrometer (resolution $4 \mathrm{~cm}^{-1}$ ) by means of OMNIC software. Data processing was done with the GRAMS software. All samples were finely ground in a mortar and pressed into self-supporting wafers $\left(15 \mathrm{mg} / \mathrm{cm}^{2}\right)$. The wafers were placed in a homemade stainless steel, vacuum cell, with $\mathrm{CaF}_{2}$ windows. High vacuum was reached by means of a turbomolecular pump and a diaphragm pump placed in line. The infrared cell was equipped with a sample holder surrounded by a heating wire for the heating steps and connected to a heated vacuum line, to avoid pyridine condensation or adsorption on the walls. Before FT-IR analysis, all samples were heated up to $450^{\circ} \mathrm{C}$ under high vacuum $\left(10^{-6}\right.$ mbar) for $1 \mathrm{~h}$ in order to desorb any physisorbed species. All spectra were collected at $150^{\circ} \mathrm{C}$ in order to eliminate the possibility of pyridine condensation. Adsorption of pyridine was realized at 1 mbar by equilibrating the catalyst wafer with the probe vapor, added in pulses for $1 \mathrm{~h}$. The desorption procedure was monitored by stepwise evacuation of the sample for $30 \mathrm{~min}$ at 150, 250, 350 and $450{ }^{\circ} \mathrm{C}$ and subsequent cooling to $150{ }^{\circ} \mathrm{C}$, recording the corresponding spectrum after each step. These temperatures represent the very weak, weak, medium and strong acid sites, respectively. The amount of acid sites was calculated using the Lambert-Beer's law and the appropriate molar extinction coefficients, using the $1450 \mathrm{~cm}^{-1}$ and $1545 \mathrm{~cm}^{-1}$ bands for the Lewis and Brønsted acid sites, respectively [26-28].

The carbon and hydrogen content of all catalyst samples was determined by elemental analysis using a LECO-800 CHN analyzer. The nature of coke deposits on the used samples was analyzed with temperature programmed oxidation (TPO) and isothermal oxidation ( $\mathrm{IO}$ ) in a home-made gas flow system equipped with a quadrupole mass analyzer (Omnistar, Balzers). Typically, the ground catalyst sample $(100 \mathrm{mg})$ was placed in a quartz reactor. For the TPO tests, the temperature was raised from room temperature to $800{ }^{\circ} \mathrm{C}$ with a heating rate of $3^{\circ} \mathrm{C} / \mathrm{min}$ in air flow $\left(100 \mathrm{~cm}^{3} / \mathrm{min}\right)$ and was maintained constant at $800^{\circ} \mathrm{C}$ for $30 \mathrm{~min}$. For the isothermal tests, the temperature was raised to the desired temperature under inert atmosphere and the flow was then switched to air $\left(100 \mathrm{~cm}^{3} / \mathrm{min}\right)$ for $3 \mathrm{~h}$. In both cases, the main $(\mathrm{m} / \mathrm{z})$ fragments registered were: $\mathrm{CO}_{2}=44, \mathrm{CO}=28, \mathrm{H}_{2} \mathrm{O}=18, \mathrm{CH}_{4}=16$ and $\mathrm{He}=4$.

Confocal fluorescence microscopy images of the used and regenerated catalyst materials were acquired with a Nikon Eclipse 90i confocal microscope with a $100 \times 0.73$ NA dry objective. Excitation light was provided by focusing three specific laser lines, i.e., 488, 561 and $642 \mathrm{~nm}$, simultaneously on the desired sample, located in an open cell (Linkam Instruments, FTIR 600). The microscope was equipped with a Nikon A1 scan head, accommodating the optics, which couple fiber optics for excitation and emission light microscope. A spectral analyzer in the Nikon A1 system was equipped with 32 photomultiplier tubes (PMTs) set to collect emission light in the region of ca. $450-700 \mathrm{~nm}$, with a resolution of $6 \mathrm{~nm}$.

\section{Results}

\subsection{Bench scale ex-situ catalytic pyrolysis of biomass}

The performance of the $\mathrm{ZrO}_{2}$-modified zeolite n-ZSM-5 extrudates in the ex-situ catalytic fast pyrolysis (CFP) of oak was initially assessed in a bench scale unit for 20 min run time at WHSV $12 \mathrm{~h}^{-1}$ and a total biomass to catalyst $(\mathrm{B} / \mathrm{C})$ ratio of 4 . The yields of the different reaction products are shown in Fig. 1. It should be noted that at least three tests were performed at each condition and averaged results are presented. The three repetitive experiments were performed with the same catalyst batch after a regeneration cycle in $40 \% \mathrm{O}_{2} / \mathrm{N}_{2}$ at $600{ }^{\circ} \mathrm{C}$. The variation in the performance was within experimental error, already signifying the robustness of the material after regeneration. A bio-oil yield of about $43 \mathrm{wt} \%$ is obtained with a water content of $18 \mathrm{wt} \%$. The rest of the reaction products consist mainly of $\mathrm{CO}_{\mathrm{x}}$ gases and solid by-product (char/coke). The high yield of decarboxylation and decarbonylation products demonstrates the high activity of the nanocrystalline ZSM-5 based catalyst in the upgrading of biomass pyrolysis vapors. This is also confirmed by the quality of the produced bio-oil, since the oxygen content in the organics is equal to $\sim 23 \mathrm{wt} \%$. Semi-quantitative analysis of the organic phase of bio-oil by GC-MS shows that the bio-oil consists mostly of oxygen-free mono-aromatics, with the rest of the compounds being mainly phenols and poly-aromatic hydrocarbons (Fig. S2).

To investigate catalyst stability, tests were performed at run times of $20 \mathrm{~min}$ and $40 \mathrm{~min}$ time-on-stream. The catalyst gradually lost cracking and deoxygenation activity, in agreement with previous reports [6,29]; this is evidenced by the increase in the organic liquid product, having a higher oxygen content, and the large decrease in water yield (Fig. 2). The amount of coke deposited on the catalyst surface also increased proportionally, already suggesting that catalyst deactivation is possibly related to coking [30]. The total gas yield remained more or less constant with increasing time-on-stream (not shown), but did show changes in composition. As summarized in Fig. 2, deactivation of the catalyst went hand in hand with a decrease in the formation of $\mathrm{CO}$ and an increase in the formation of $\mathrm{CO}_{2}$. These data are in agreement with results reported by Vitolo et al. [11] and Ibanez et al. [15] on the deactivation of zeolite ZSM-5 catalysts in bio-oil upgrading.

\subsection{Properties of spent and regenerated catalysts}

The spent catalysts obtained after 20 and 40 min reaction time were subjected to a regeneration procedure at three different temperatures (i.e. $400{ }^{\circ} \mathrm{C}, 500{ }^{\circ} \mathrm{C}$ and $600^{\circ} \mathrm{C}$ ) for $3 \mathrm{~h}$ in a static furnace. The fresh, used and regenerated samples were thoroughly characterized to assess the impact of deactivation and regeneration on

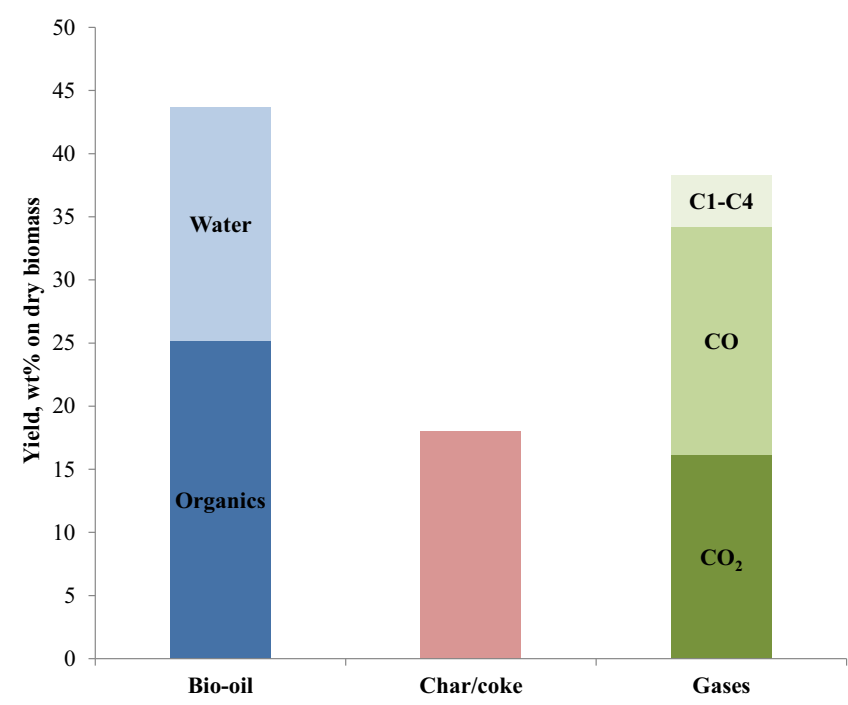

Fig. 1. Pyrolysis product yields at run time $20 \mathrm{~min}\left(\mathrm{WHSV}=12 \mathrm{~h}^{-1}, \mathrm{~B} / \mathrm{C}=4\right)$. 

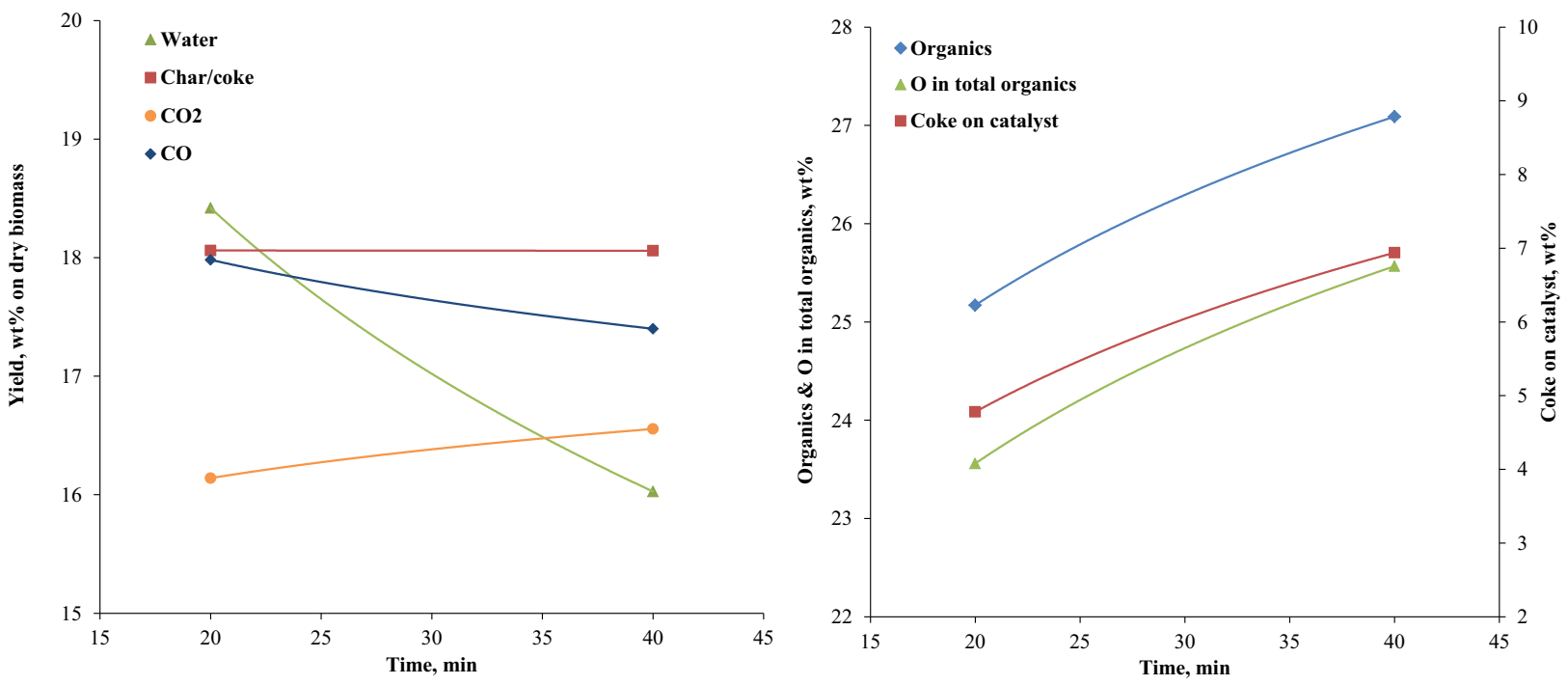

Fig. 2. Pyrolysis product yields and coke on catalyst as a function of run time.

Table 1

Textural properties of the fresh, deactivated and regenerated samples.

\begin{tabular}{|c|c|c|c|c|c|c|c|c|c|c|}
\hline \multicolumn{2}{|c|}{ Property } & Fresh & Used20 & Used40 & Reg20_400 & Reg20_500 & Reg20_600 & Reg40_400 & Reg40_500 & Reg40_600 \\
\hline \multicolumn{2}{|c|}{$\mathrm{S}_{\mathrm{BET}}\left(\mathrm{m}^{2} / \mathrm{g}\right)$} & 303 & 255 & 250 & 296 & 294 & 296 & 293 & 301 & 298 \\
\hline \multicolumn{2}{|c|}{$\mathrm{S}_{\mathrm{Ext}}\left(\mathrm{m}^{2} / \mathrm{g}\right)$} & 130 & 102 & 103 & 103 & 118 & 114 & 124 & 119 & 120 \\
\hline \multicolumn{2}{|c|}{$\mathrm{S}_{\text {Micropore }}\left(\mathrm{m}^{2} / \mathrm{g}\right)$} & 173 & 153 & 147 & 180 & 176 & 182 & 169 & 182 & 178 \\
\hline \multicolumn{2}{|c|}{ Total PV $\left(\mathrm{cm}^{3} / \mathrm{g}\right)$} & 0.58 & 0.47 & 0.49 & 0.50 & 0.55 & 0.50 & 0.56 & 0.53 & 0.53 \\
\hline \multicolumn{2}{|c|}{$\mathrm{V}_{\text {Macro }}\left(\mathrm{cm}^{3} / \mathrm{g}\right)$} & 0.12 & 0.09 & 0.10 & 0.12 & 0.11 & 0.11 & 0.13 & 0.12 & 0.13 \\
\hline \multicolumn{2}{|c|}{$\mathrm{V}_{\text {Meso }}\left(\mathrm{cm}^{3} / \mathrm{g}\right)$} & 0.38 & 0.31 & 0.32 & 0.30 & 0.36 & 0.31 & 0.35 & 0.33 & 0.32 \\
\hline \multicolumn{2}{|c|}{$V_{\text {Micropore }}\left(\mathrm{cm}^{3} / \mathrm{g}\right)$} & 0.08 & 0.07 & 0.07 & 0.08 & 0.08 & 0.08 & 0.08 & 0.08 & 0.08 \\
\hline \multirow{2}{*}{ Coke } & C (wt. \%) & - & 4.80 & 6.90 & 0.50 & - & - & 0.50 & - & - \\
\hline & H (wt. \%) & - & 0.03 & 0 & 0.13 & - & - & 0.20 & - & - \\
\hline
\end{tabular}

the physicochemical properties of the catalyst (Table 1 ). The fresh catalyst presents a relatively complex porosity, consisting of zeolitic micropores and additional macro/mesopores associated with the voids existing between the ZSM- 5 nanocrystals and the attapulgite needles. While the micropores represent just about $14 \%$ of the total pore volume, they contribute to $57 \%$ of the BET surface area. Expectedly, the BET surface area of the $\mathrm{ZrO}_{2}$-modified zeolite ZSM-5 catalyst decreased after reaction. Both the macro/ mesopore and micropore surface areas were affected, with the decrease being stronger for the former. Similar observations pertain also to the pore volume. Thus, taking into account the overall reduction of the pore volume in the used catalysts (c.a. $0.1 \mathrm{~cm}^{3} / \mathrm{g}$ ), about $90 \%$ of it corresponds with macro/mesopores and just $10 \%$ is associated with micropores. This finding suggests that the coke deposits are formed mostly outside the zeolite micropores. The differences between the used 20 and used 40 samples are very small, indicating that the major part of the deactivation occurs early in the reaction. Regeneration at all investigated temperatures largely recovered the original surface area and porosity, showing the effectiveness of this treatment in removing most of the coke deposits.

All samples exhibit the characteristic diffraction pattern of the orthorhombic phase of zeolite ZSM-5 (PDF 00-044-0003) (Fig. 3) [31,32]. No clear XRD peaks originating from a crystalline $\mathrm{ZrO}_{2}$ phase are observed for any of the samples [33,34]. Although the catalyst retains its orthorhombic crystalline structure after the pyrolysis reaction, even for prolonged time-on-stream, some small changes are observed. In addition to the lower intensity of the zeolite ZSM-5 main XRD peaks, Fig. 3a shows the merge of the split peaks at $2 \theta 23.2$ (inset ii) and $45.4^{\circ}$ seen for the fresh sample into a single peak after reaction. In addition, the peak at $23.2^{\circ}$ is enlarged in intensity compared to the peak at $24.0^{\circ}$, as compared to the fresh catalyst sample (inset ii). This enlargement can be directly attributed to the incorporation of organics within the zeolite pores $[31,35]$. The estimated intensity differences are very similar for both the used20 and used40 (see values in Table S1), suggesting that the coke build-up in the zeolite occurs mostly within the first $20 \mathrm{~min}$ of reaction, in line with the BET results.

Upon regeneration, the intensity of the low angle diffraction peaks at 8.0 and $8.9^{\circ}$ in the regenerated samples increased again compared to the used samples (Fig. 3b(i)) [31,35]. In addition, the split peaks at $2 \theta 23.2^{\circ}$ (inset ii) and $45.4^{\circ}$ reappeared after regeneration. Surprisingly, this signal recovery is stronger for the reg40 than for the reg20 samples (Fig. 3b). Also, the difference in intensity between the XRD peaks at $23.2^{\circ}$ and $24.0^{\circ}$ considerably reduced after regeneration (Table $\mathrm{S} 1$ ), indicating that organics/ impurities previously incorporated within the pores are effectively removed [31]. For the reg40 samples, the peak located at ca. $26.6^{\circ}$ was more intense and sharper than for the used40, but less than for the fresh catalyst. This XRD peak may be attributed to the attapulgite phase, suggesting a possible re-dispersion of the attapulgite binder upon reaction. Alternatively the better resolution of the $26.6^{\circ}$ XRD peak could be due to the disappearance of the graphite peak of coke, which locates at a very similar position to quartz [3638].

Changes in aluminum speciation in the fresh, used 40 and reg 40 samples after regeneration at $400{ }^{\circ} \mathrm{C}, 500^{\circ} \mathrm{C}$ and $600^{\circ} \mathrm{C}$ were examined by solid-state $1 \mathrm{D}{ }^{27} \mathrm{Al}$ MAS (Fig. 4a) and ${ }^{27} \mathrm{Al}$ MQ MAS ssNMR (Fig. 4b-e) analyses. Expectedly, the ssNMR spectrum of the fresh sample (red series) showed the presence of mainly framework tetrahedral $\left(\mathrm{Al}^{\mathrm{IV}}, 54 \mathrm{ppm}\right)$ and some extra-framework octa- 

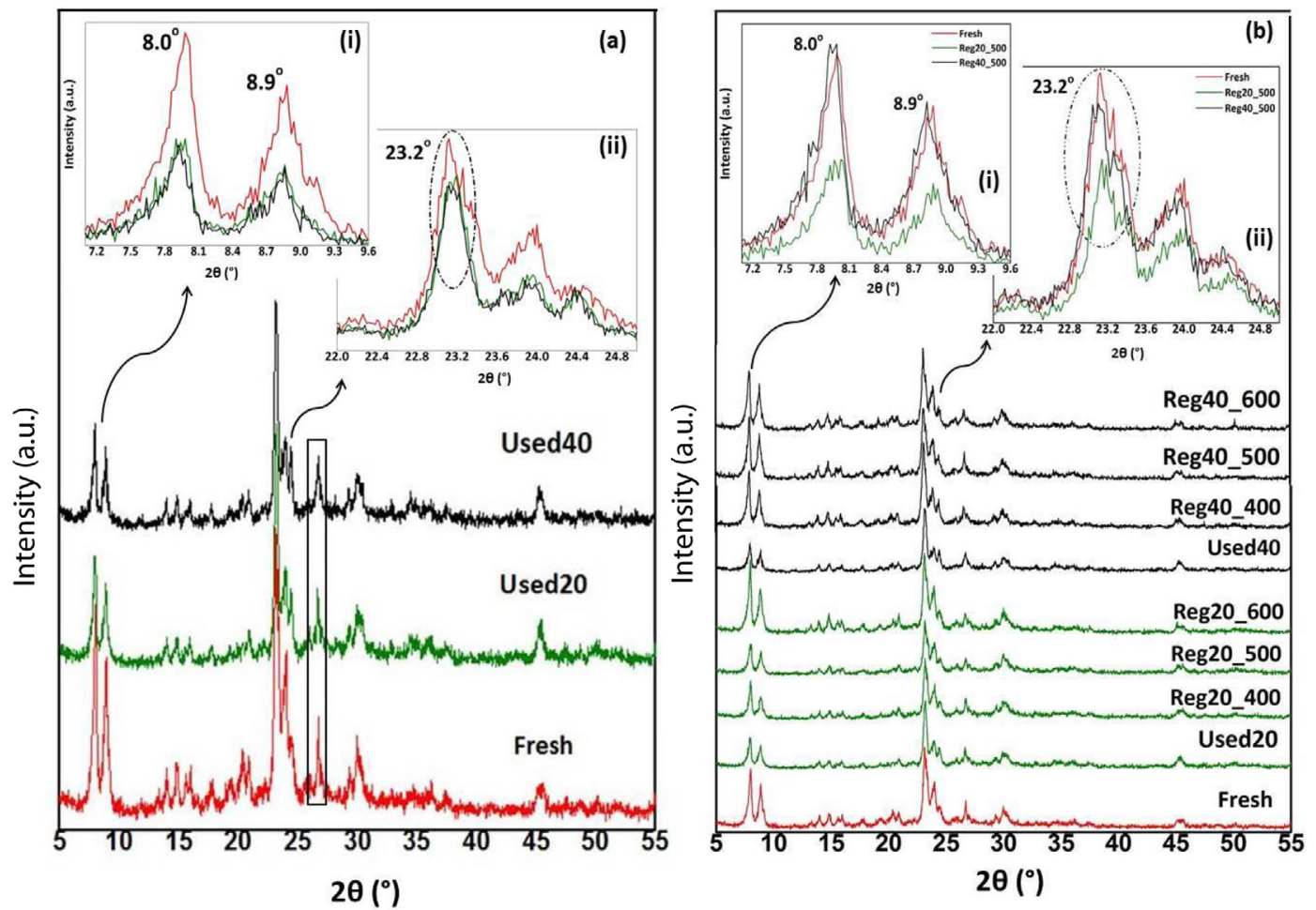

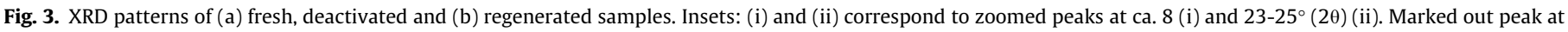
$26.6^{\circ}$ could be assigned to quartz/graphite

hedral $\left(\mathrm{Al}^{\mathrm{VI}}, 2 \mathrm{ppm}\right) \mathrm{Al}$ species $[39,40]$. After reaction, the concentration of tetrahedral Al sites is lower than in the fresh sample, with its peak maximum shifting upfield to $52 \mathrm{ppm}$, affected by coke formation $[12,41,42]$. The anisotropy of the tetrahedral Al signal in the used40 sample (black series) is readily evidenced by MQ MAS analysis (b), indicating that the framework Al species suffer from distortion upon reaction. As for the extra-framework Al sites, the spectrum of the spent sample showed these to be less defined, broadly distributing in the hump formed at 30 to $-20 \mathrm{ppm}$, including penta-coordinated, whose resonance typically locates at ca. $30 \mathrm{ppm}$ [12], and octahedrally coordinated $\mathrm{Al}^{\mathrm{V}}$ species. The larger diversity of $\mathrm{Al}$ environments in the spent samples is probably related to the interaction of the $\mathrm{Al}$ species with organic compounds present in the coke deposits, affecting their coordination.

After regeneration at $400{ }^{\circ} \mathrm{C}$ (blue series), the original features were recovered, with the increased anisotropy seen in the used sample being significantly reduced (c), resulting in an almost complete recovery of the original intensity and peak position of the tetrahedrally coordinated $\mathrm{Al}$ ( $\mathrm{a}$, inset). The same was observed for the extra-framework octahedral Al species, located at ca. $2 \mathrm{ppm}$. For the reg40_500 sample, $\mathrm{Al}^{\mathrm{IV}}$ species are located at $53 \mathrm{ppm}$ (orange series, inset in a, d), between the resonances shown by the fresh and the used 40 sample; two types of $\mathrm{Al}^{\mathrm{VI}}$ species were evidenced by clear resonances at $2 \mathrm{ppm}$ and $0 \mathrm{ppm}$, indicating also some degree of distortion when compared to the fresh sample. For the reg40_600 sample, the tetrahedral $\mathrm{Al}^{\mathrm{IV}}$ species remained at the same position as in the used40 sample (green series, inset a, e). Also the broad signal at 30 to -20 ppm, which corresponds to miscellaneous extra-framework $\mathrm{Al}$ species, is maintained, the octahedrally coordinated $\mathrm{Al}^{\mathrm{VI}}$ species being however better defined. The ssNMR results suggest that any changes in the $\mathrm{Al}$ environment/coordination induced during reaction are more efficiently reversed at lower combustion temperatures. Higher combustion temperatures provoke zeolite dealumination effects, thought to be the result of harsher steaming upon coke combustion. Yet, the limited and, in principle, reversible changes in $\mathrm{Al}$ speciation rule out zeolite dealumination as a main deactivating factor for the used40 sample. By inference, any changes in $\mathrm{Al}$ speciation in used20 sample (not measured) are expected to be less or at most the same as for the used40 sample.

The morphology and structure of the fresh, used and regenerated catalyst samples was examined by scanning electron microscopy (SEM) as well as transmission electron microscopy (TEM). SEM images of the fresh sample (Fig. S3) showed aggregates (20-50 $\mu \mathrm{m})$ consisting of zeolite ZSM-5 nanocrystals between 30 and $100 \mathrm{~nm}$. As shown by TEM, the zeolite crystals are embedded within agglomerated needle-like clay mineral crystals (typical dimensions $0.5 \mu \mathrm{m} \times 30 \mathrm{~nm}$ ) (Fig. 5a) [43]. Next to the zeolite (i.e., ZSM-5) and the clay mineral (i.e., attapulgite) crystals, three additional other solids could be identified in the TEM images: $\mathrm{ZrO}_{2}$ nanoparticles (ca. $3 \mathrm{~nm}$ ) of rugged morphology [44], identified with the digit 1 in Fig. 5 and Figs. S4-S6; bigger $(25-50 \mathrm{~nm})$ spherical shapes (2), which might correspond to quartz, a common impurity in attapulgite [45,46]; and amorphous carbonaceous deposits [47-49] and graphite flakes (3) [36,37,50]. TEM examination revealed the used samples to be more agglomerated than the fresh, in particular after 40 min reaction (Fig. 5c, Fig. S4g,i). Amorphous carbonaceous deposits are abundantly present, co-existing with the zeolite crystals and with a seemingly re-dispersed attapulgite phase in the catalyst sample after use for $40 \mathrm{~min}$, in agreement with the XRD results.

The morphology of the regenerated catalysts after 20 min reaction time remained largely unaltered compared to the used20 sample (Fig. 5d, Fig. S6a,b), except for a higher degree of agglomeration in the reg20_600 sample (f), as well as bigger spherical particles, as highlighted in region 2, assigned to quartz impurities of attapulgite. Such spherical quartz particles can be easily confused with a sintered $\mathrm{ZrO}_{2}$ phase, both distributing randomly but frequently. Smaller rugged-like nanoparticles, identified in region 1 for the fresh and used samples and assigned to intact $\mathrm{ZrO}_{2}$ particles, are less frequently seen. In reg40 samples, $\mathrm{ZrO}_{2}$ nanoparticles appeared slightly more agglomerated, especially at higher combus- 

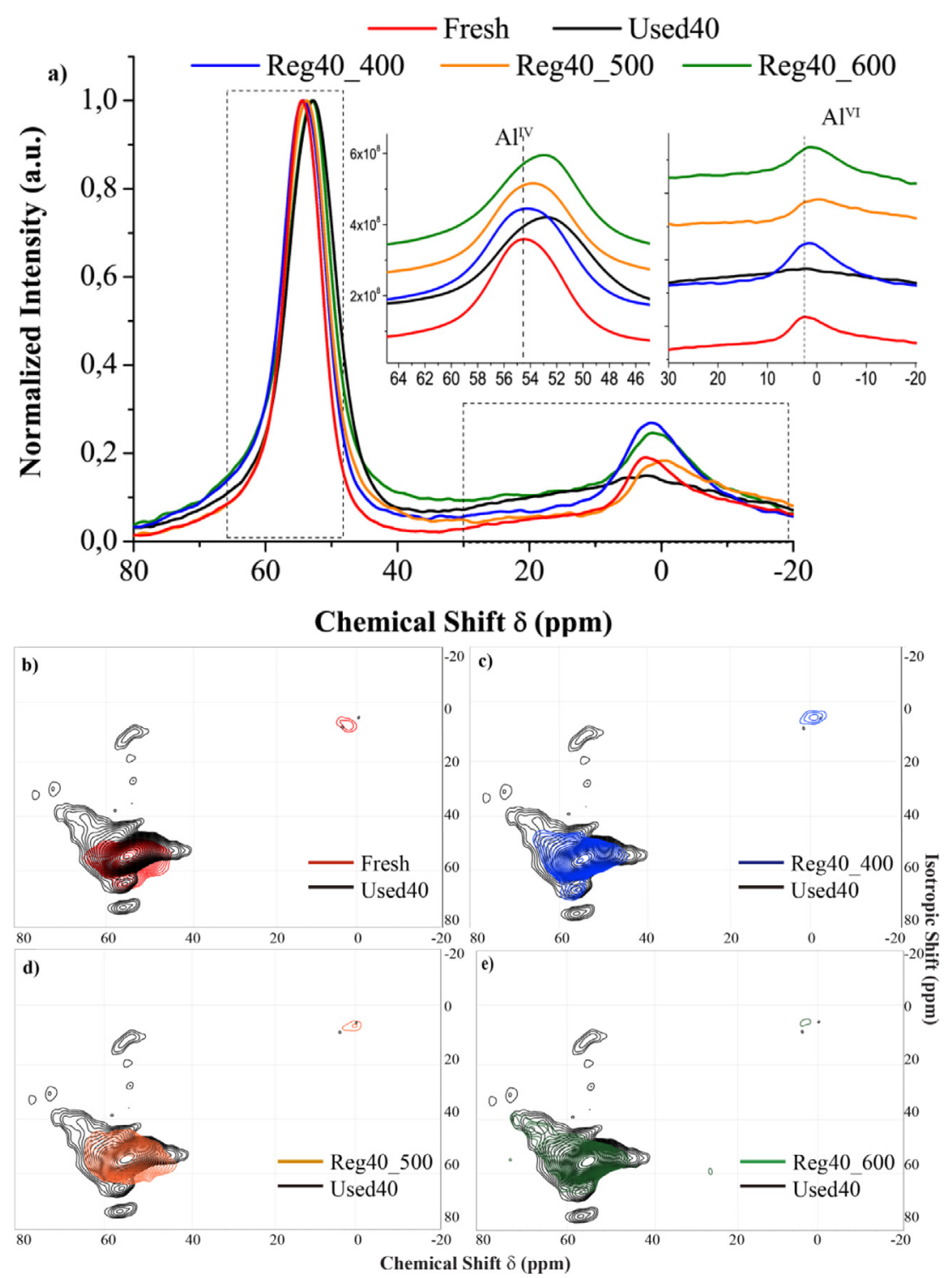

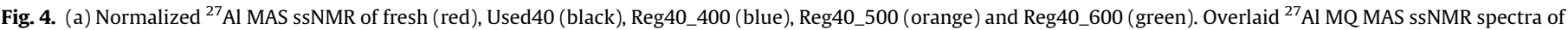
Used40 (black) and: (b) Fresh, (c) Reg40_400, (d) Reg40_500 and (e) Reg40_600 samples.

tion temperature, as represented by reg40_600 (i). Remaining graphite coke flakes could also be distinguished (region 3 ) in reg40_400 (g).

\subsection{Acidity of the spent and regenerated catalysts}

The total acidity and the type of acid sites determined by pyridine FT-IR spectroscopy are presented in Table 2 for the fresh, deactivated and regenerated samples. All materials exhibit Brønsted acidity, mainly attributed to the presence of zeolite ZSM-5, and Lewis acid sites, provided by the zeolite, the attapulgite binder and the $\mathrm{ZrO}_{2}$ phase [51]. After 20 min of reaction, the catalyst loses half of its acidity, with a similar degree of reduction in both types of sites (used20 sample). Longer exposure to reaction conditions leads only to additional decrease in Lewis acid sites, with the Brønsted sites showing no further drop in abundance or strength (Fig. 6). Regeneration resulted in the recovery of the acidic properties, the extent depending both on the duration of the pyrolysis reaction and the regeneration temperature. Better recovery was attained upon regeneration at $500{ }^{\circ} \mathrm{C}$, with both the $400{ }^{\circ} \mathrm{C}$ and $600{ }^{\circ} \mathrm{C}$ treatments leading to lower total acidity. This applies also to the strength of the recovered Brønsted acid sites, as shown in Fig. 6. In the case of the low temperature regeneration, the effects are most probably related to incomplete coke combustion, as discussed below. The acidity reduction is more severe at $600{ }^{\circ} \mathrm{C}$, possibly due to the above commented dealumination taking place at this coke combustion temperature. Yung et al. [14] also reported lower Brønsted/Lewis acid ratio and lower bridging vs. non-framework -OH vibrations on HZSM-5 regenerated at $700{ }^{\circ} \mathrm{C}$ (after biomass CFP) as compared to the fresh sample. This was attributed to the conversion of Brønsted to Lewis acid sites due to high temperature steaming during regeneration. With regards to the pyrolysis time, contrary to expectations, the recovery of the acidic properties is higher in the regenerated samples after $40 \mathrm{~min}$ reaction time compared to the regenerated ones after 20 min pyrolysis.

\subsection{Nature and location of coke deposits}

\subsubsection{Temperature programmed and isothermal oxidation}

Temperature programmed oxidation (TPO) was performed to investigate the nature of coke formed over the $\mathrm{ZrO}_{2}$-modified 


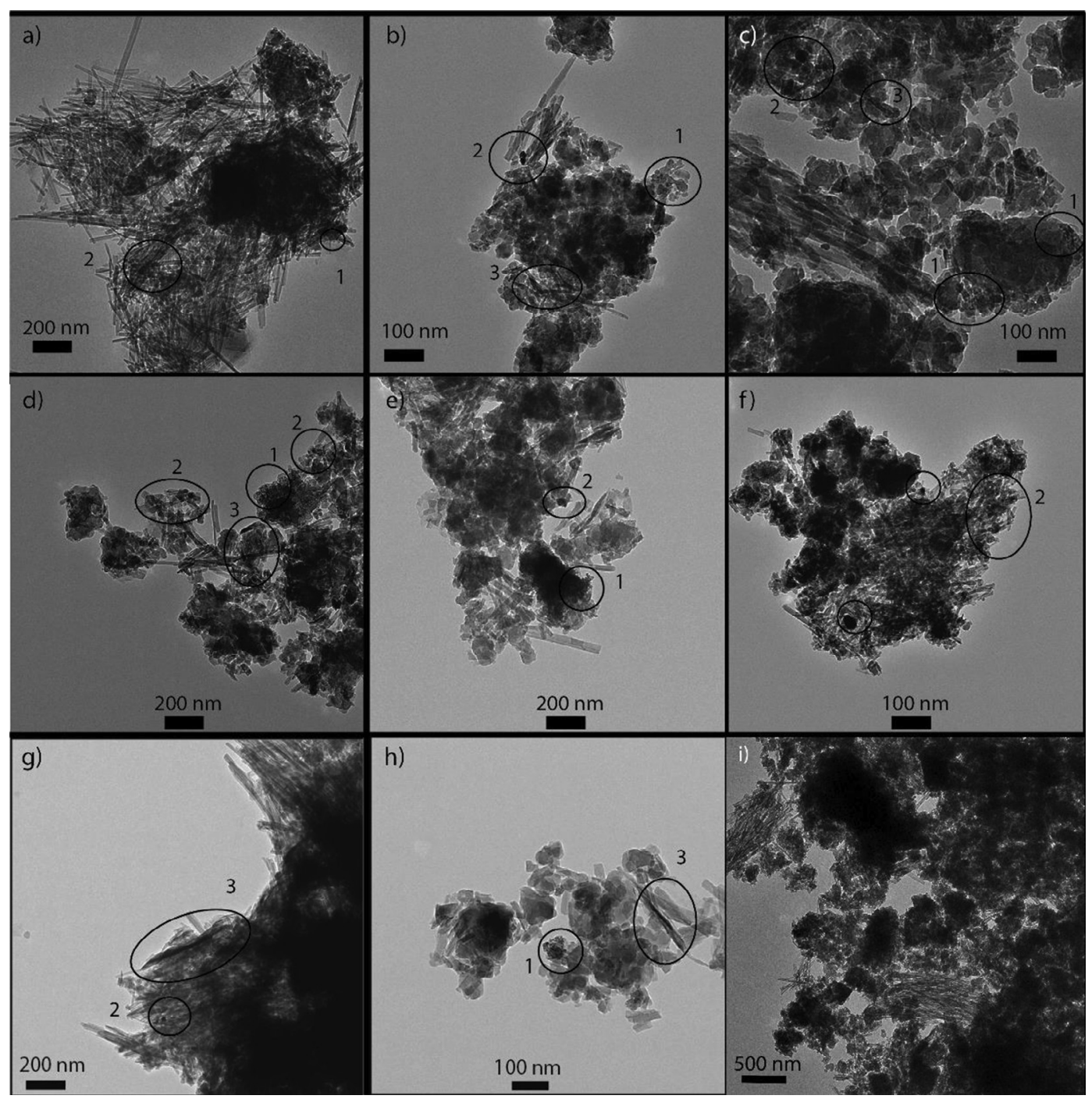

Fig. 5. TEM images of Fresh (a), Used20 (b), Used40 (c), Reg20_400 (d), Reg20_500 (e), Reg20_600 (f), Reg40_400 (g), Reg40_500 (h) and Reg40_600 (i).

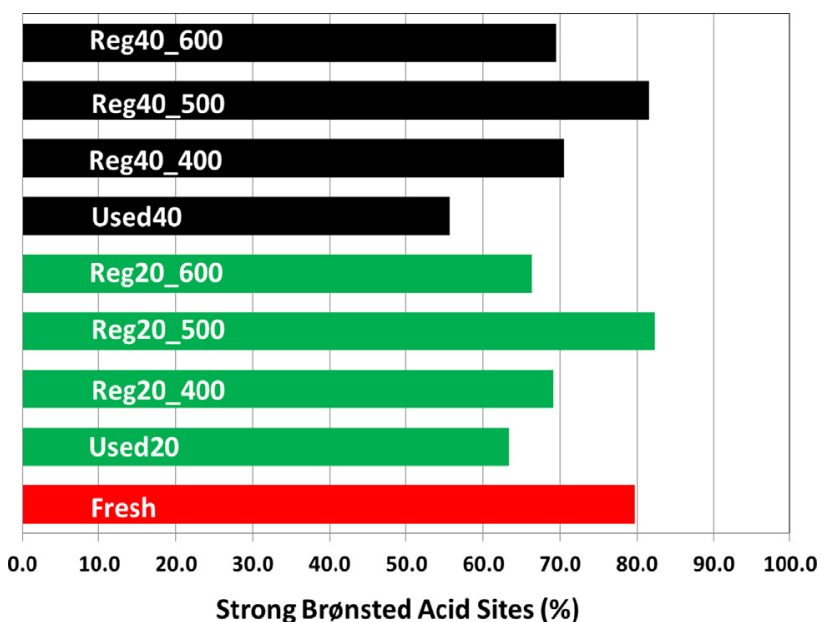

Fig. 6. Percentage of the strong Brønsted acid sites in the fresh, used and regenerated catalyst samples.

zeolite ZSM-5 deactivated samples. Both samples present one main $\mathrm{CO}_{2}$ evolution peak, with maxima at $415^{\circ} \mathrm{C}$ and $406{ }^{\circ} \mathrm{C}$ for used20 and used40, respectively (Fig. 7). As expected, the emitted $\mathrm{CO}_{2}$ was

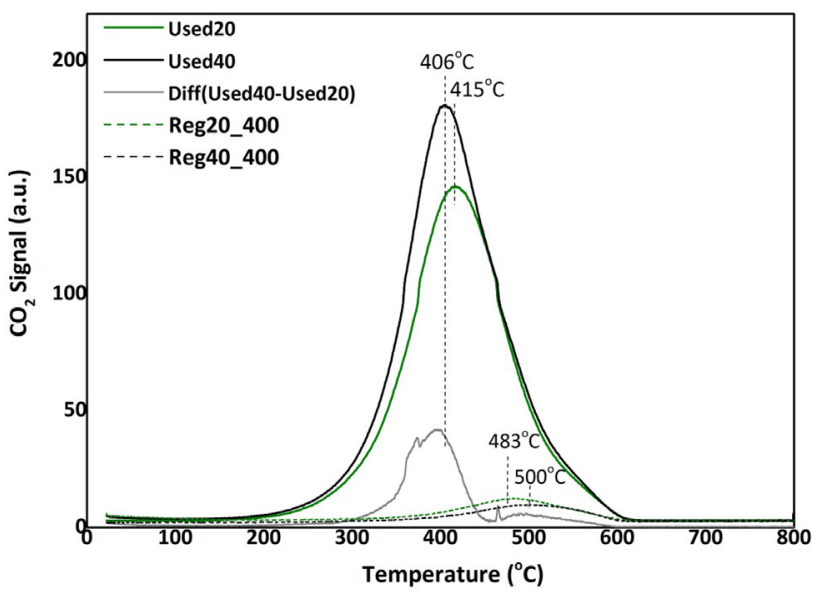

Fig. 7. Temperature programmed oxidation (TPO) profiles of the deactivated catalyst samples.

higher for used40, in line with its larger coke content. In both samples the $\mathrm{CO}_{2}$ profile is quite broad, extending from $\sim 150-620^{\circ} \mathrm{C}$. This suggests the presence of coke species of different nature 
(i.e., soft and harder coke) and location within the catalyst structure (i.e., intra-porous and external coke). The difference between the $\mathrm{CO}_{2}$ evolution profiles of the two deactivated samples is also shown in Fig. 7. It can be clearly observed that the "extra" coke forming on the technical catalyst from 20 to 40 min reaction time is mainly of soft type, i.e. hydrogen-rich forms of coke deposits that can be easily removed with oxidation at relatively low temperatures.

TPO was conducted also after regeneration at the three investigated temperatures. No $\mathrm{CO}_{2}$ evolution was observed for the samples regenerated at $500{ }^{\circ} \mathrm{C}$ and $600{ }^{\circ} \mathrm{C}$. In contrast, a $\mathrm{CO}_{2}$ peak of low intensity was detected for the two regenerated catalyst samples at $400{ }^{\circ} \mathrm{C}$, located in the $480-500^{\circ} \mathrm{C}$ range (Fig. 7 , dashed lines). The high maximum temperature of this peak suggests that it is related with the combustion of the remaining graphite coke flakes observed by TEM. Elemental analysis confirmed the complete removal of coke after regeneration at $500^{\circ} \mathrm{C}$ and $600^{\circ} \mathrm{C}$, whereas a small amount $(\sim 0.5 \mathrm{wt} \%)$ still remained on both samples after coke oxidation at $400{ }^{\circ} \mathrm{C}$ (Table 1$)$. This is also apparent visually, as the black used samples regained the initial color of the fresh catalyst after regeneration at high temperatures, while they remained grey after regeneration at $400{ }^{\circ} \mathrm{C}$ (see also the image in Fig. 9).

Isothermal oxidation (IO) experiments under air flow were carried out to investigate the rate of coke combustion at $400{ }^{\circ} \mathrm{C}, 500{ }^{\circ} \mathrm{C}$ and $600{ }^{\circ} \mathrm{C}$. Fig. $8 \mathrm{a}$ presents the $\mathrm{CO}_{2}$ signal for the first $10 \mathrm{~min}$ of the isothermal oxidation test. The $\mathrm{CO}_{2}$ peak became bigger and sharper as the oxidation temperature increased due to the higher coke combustion rate. The integration of the $\mathrm{CO}_{2}$ signal is presented in Fig. 8b, expressed as amount of remaining carbon on the catalyst versus time. At $600{ }^{\circ} \mathrm{C}$, coke combustion proceeded rapidly on both samples and was completed in the first $10 \mathrm{~min}$ of the isothermal oxidation test. The combustion behavior was similar at $500{ }^{\circ} \mathrm{C}$, albeit with lower rate. On the other hand, the rate of coke combustion was very slow at $400^{\circ} \mathrm{C}$, with significant differences observed between the two samples. In used20, only about $30 \%$ of the coke was removed in the first $10 \mathrm{~min}$ of isothermal oxidation at $400{ }^{\circ} \mathrm{C}$, with a relatively constant rate as a function of time. The used 40 catalyst initially exhibited a high coke oxidation rate for the first minute, similar to that recorded at $500{ }^{\circ} \mathrm{C}$ and $600{ }^{\circ} \mathrm{C}$, probably attributed to the presence of easily-oxidized soft coke. The reaction then slowed down, indicative of oxidation of harder-to-remove coke species similar to those present in the used 20 sample, leading overall to only $45 \%$ removal of the coke after $10 \mathrm{~min}$. Similar results have also been reported for the regeneration of ZSM-5 following catalytic fast pyrolysis of pine at regeneration temperatures ranging from $500{ }^{\circ} \mathrm{C}$ to $700{ }^{\circ} \mathrm{C}$ [14]. Full coke removal was observed at temperatures exceeding $650^{\circ} \mathrm{C}$; higher than the temperature determined in this work. This difference could be attributed to the conditions of the regeneration, as in the above-mentioned work the oxidative treatment was performed in $4 \% \mathrm{O}_{2} / \mathrm{N}_{2}$ as opposed to the use of air that we employed.

\subsubsection{Confocal fluorescence microscopy}

To study the spatial distribution of the (fluorescent) coke formed on the deactivated samples, the catalyst extrudates were studied by confocal fluorescence microscopy [52]. The confocal fluorescence microscopy images of the fresh, used and regenerated catalyst extrudates are shown in Fig. 9. The deactivated samples were almost totally black due to the formed coke. The used $\mathrm{ZrO}_{2} /$ n-ZSM-5-ATP catalyst extrudates were studied both at the external surface and over a cross-section of the catalyst bodies with the 488 , 561 and $642 \mathrm{~nm}$ excitation lasers.

Representative confocal fluorescence microscopy images for used20 (i) and used40 (ii) samples are shown in Fig. 10, with the corresponding spectral information. The cross-section of the used20 catalyst extrudate showed an egg-shell spatial distribution of the coke deposits (see Fig. 9b). When the catalyst surface is irradiated, no fluorescence could be detected due to the high polyaromaticity or (even) graphitic nature of the coke formed, which absorbed all incident light and did not allow for light emission (Fig. 10i,a). Nevertheless, the fluorescence progressively increased in intensity when moving from the edge (Fig. 10i,b, see spectrum for B) to the center of the extrudate (Fig. 10i,b,c, see spectrum for A) of the catalyst extrudate, where the coke is very polyaromatic, i.e. H-poor, but less than for B, showing more intense fluorescence, as confirmed by the emission bands (d). There are also regions (C) with a higher presence of naphthalene/anthraceneslike species (emitting light at $400-550 \mathrm{~nm}$ ) [53] than polyaromatic-like species (emitting over $550 \mathrm{~nm}$ ). These regions of softer coke can tentatively be assigned to $\mathrm{ZrO}_{2}$ and/or attapulgite domains with lower concentration of Brønsted acid sites that do not favor the formation of poly-aromatics or hard coke.

Confocal fluorescence microscopy analysis of the used40 catalyst extrudate (Fig. 10ii) showed lack of fluorescence at the edge of the cross-section (ii,b), differentiating this sample from the used20 catalyst extrudate. The center still remained fluorescent though (c-f). Coke continued to accumulate in a radial direction with run time, which illustrates that diffusion is not totally blocked. The analysis of different zones for the used 40 catalyst extrudate was very similar to used20. Regions with high fluorescence and large presence of poly-aromatics (i.e., region $A$ ), regions closer to the edge of the extrudate and thus less intense (i.e., region B), as well as regions with higher presence of naphthalene/ anthracenes (i.e., region $C$ ) could be distinguished. Note that the lower intensity of the A regions in used 40 compared to used20 is due to the darker coloration of the former given the more dominant presence of coke.

Considering that coke is not fully burned off upon regeneration at $400{ }^{\circ} \mathrm{C}$, the remaining coke on reg20_400 and reg40_400 samples was also studied by confocal fluorescence microscopy and the results are shown in Fig. 11. In the reg20_400 extrudate, the poly-aromatic fraction of coke was considerably reduced upon regeneration at $400{ }^{\circ} \mathrm{C}$. The fluorescence, now yellowish, showed the presence of less conjugated poly-aromatics whose maximum emission peak was located at $\lambda \sim 600 \mathrm{~nm}$ on the catalyst surface, and at $\lambda \sim 560 \mathrm{~nm}$ on the cross-section (Fig. 11i,d), compared to used20 where it was located at $\lambda \sim 660 \mathrm{~nm}$ on the cross-section (Fig. 11i). Yet, even after partial coke combustion, the coke (precursor) species were still distributed in an egg-shell manner, being more concentrated on the catalyst extrudate surface - forming a dark grey ring (Fig. 9) - than at the center of the catalyst extrudate. This was visually confirmed by the confocal fluorescence microscopy images and the related emission spectra, which showed species emitting light at longer wavelengths at the surface (i.e., region A) than in the center of the extrudate (i.e., regions B and C). The same observations are made for reg40_400, with most of the condensed poly-aromatic coke gone after regeneration (Fig. 11ii,a). A considerable amount of poly-aromatics was still present, however, emitting red fluorescence on the catalyst extrudate surface with a maximum absorption peak $\sim 640 \mathrm{~nm}$ (A). Also here, the egg-shell spatial distribution of coke could still be observed after regeneration (Fig. 11ii) (B, C, see spectral info in d).

\section{Discussion}

Bench scale tests of catalytic fast pyrolysis (CFP) of biomass performed in ex-situ mode, i.e. by using two close-coupled reactors, over $\mathrm{ZrO}_{2} / \mathrm{n}$-ZSM-5-ATP catalyst extrudates showed that the catalyst deactivates with increasing time-on-stream. Deactivation led to decreased activity in the cracking and deoxygenation reactions, resulting in higher oxygen content in the liquid organic fraction. 
Table 2

Total acidity (Brønsted and Lewis) for the fresh catalyst and deactivated samples.

\begin{tabular}{|c|c|c|c|c|}
\hline \multirow{2}{*}{ Sample } & \multirow{2}{*}{ Total Acidity $(\mu \mathrm{mol} / \mathrm{g})$} & \multicolumn{2}{|c|}{ Type of acid sites } & \multirow{2}{*}{ Brønsted/Lewis Ratio (B/L } \\
\hline & & Brønsted $(\mu \mathrm{mol} / \mathrm{g})$ & Lewis $(\mu \mathrm{mol} / \mathrm{g})$ & \\
\hline Fresh & 111.6 & 46.2 & 65.4 & 0.71 \\
\hline Used20 & 60.3 & 25.8 & 34.6 & 0.74 \\
\hline Used40 & 39.1 & 27.5 & 11.6 & 2.40 \\
\hline Reg20_400 & 89.9 & 36.7 & 53.2 & 0.69 \\
\hline Reg20_500 & 104.3 & 49.2 & 55.1 & 0.89 \\
\hline Reg20_600 & 81.0 & 27.2 & 53.8 & 0.51 \\
\hline Reg40_400 & 101.0 & 43.7 & 57.3 & 0.76 \\
\hline Reg40_500 & 110.4 & 43.4 & 67.0 & 0.65 \\
\hline Reg40_600 & 83.2 & 30.8 & 52.4 & 0.59 \\
\hline
\end{tabular}

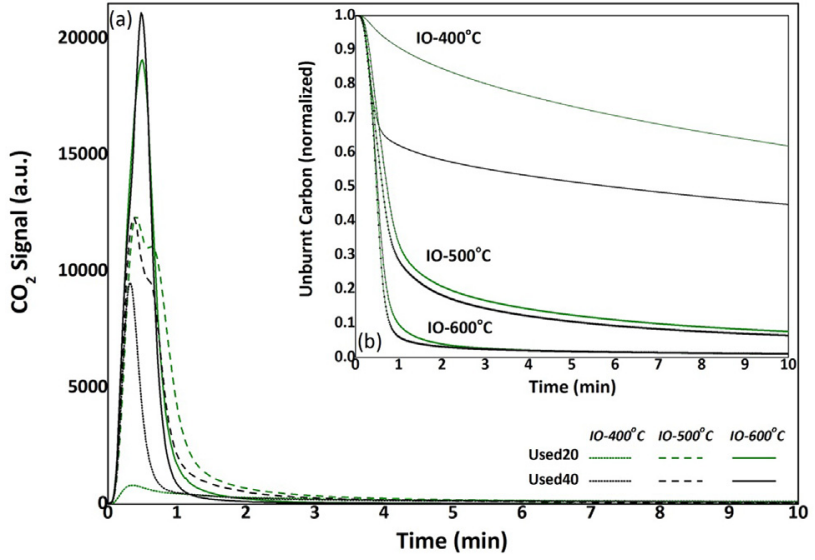

Fig. 8. (a) Isothermal oxidation profiles and (b) cumulative curves of the deactivated samples (unburnt carbon) at $400{ }^{\circ} \mathrm{C}, 500{ }^{\circ} \mathrm{C}$ and $600{ }^{\circ} \mathrm{C}$ for the used 20 (green curves) and used40 (black curves) samples.

In-depth characterization of the spent catalyst extrudates after $20 \mathrm{~min}$ and $40 \mathrm{~min}$ reaction time and after regeneration at $400{ }^{\circ} \mathrm{C}, 500^{\circ} \mathrm{C}$ and $600{ }^{\circ} \mathrm{C}$ in air with various characterization techniques allowed for an overall assessment of the origins of catalyst deactivation as a function of time-on-stream and the effect of regeneration as a function of the applied temperature.
Despite the significant amount of coke deposition (i.e., $4.8 \mathrm{wt} \%$ after $20 \mathrm{~min}$ and $6.9 \mathrm{wt} \%$ after $40 \mathrm{~min}$ reaction), the catalyst material retained to a large extent its surface area, pore volume, crystallinity and morphology. The most significant alteration occurred in acidity that progressively decreased with reaction time, with Brønsted and Lewis acid sites being influenced differently, however. Within the first 20 min of the reaction, a similar reduction $(-43-45 \%)$ in both types of acid sites was seen. The hindered access to both types of acid sites is therefore indicative of blockage of the zeolite domains by coke deposits. This hypothesis is supported by the XRD and ssNMR results that showed that the framework Al sites undergo small distortions due to the incorporation of organics within the zeolite pores. Catalyst particle agglomeration and sintering and/or segregation of the $\mathrm{ZrO}_{2}$ phase could be also occurring; however, the extension and contribution is considered to be small since the catalyst regenerated at $500^{\circ} \mathrm{C}$ exhibited physicochemical properties very similar to those of the fresh one. On the other hand, changes in the acid site strength also occurred, with a $25 \%$ decrease in the number of strong Brønsted sites in the used20 sample. Removal of the strong Brønsted sites by dealumination can be ruled out on the basis of the obtained ssNMR results, which furthermore showed that the changes that occur are largely reversible. Hence, it can be argued that coke preferentially deposits on the strong Brønsted acid sites, as confocal fluorescence microscopy measurements showed $[8,54,55]$. It is well-established that the acidic sites of HZSM-5, particularly the strong Brønsted sites, catalyze the cracking of the oxygenates in pyrolysis vapors. In
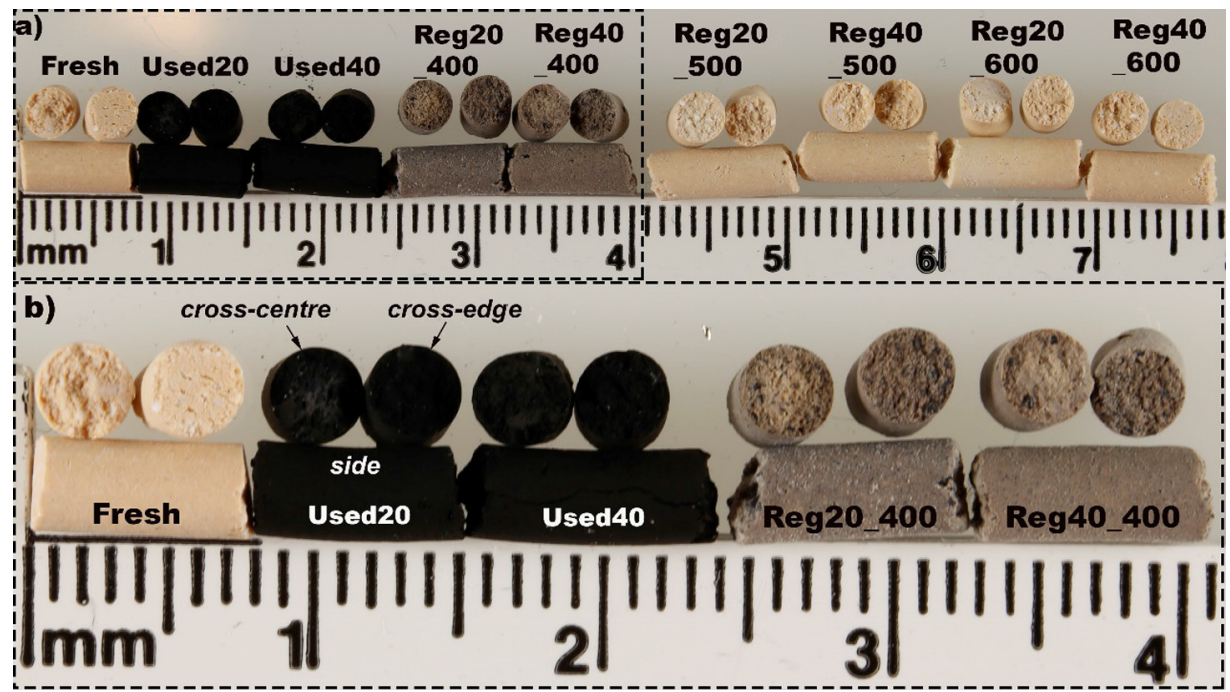

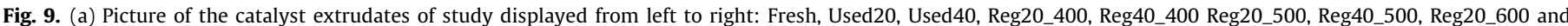

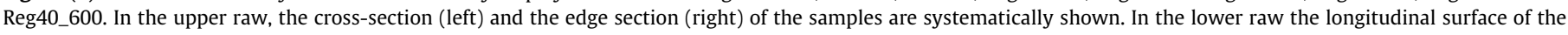

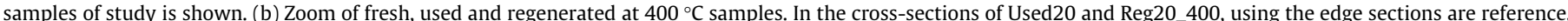

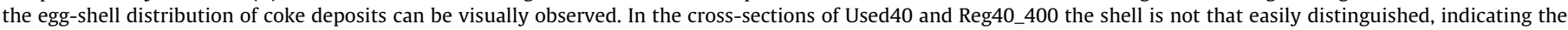
progress of coke distribution with longer reaction times. 


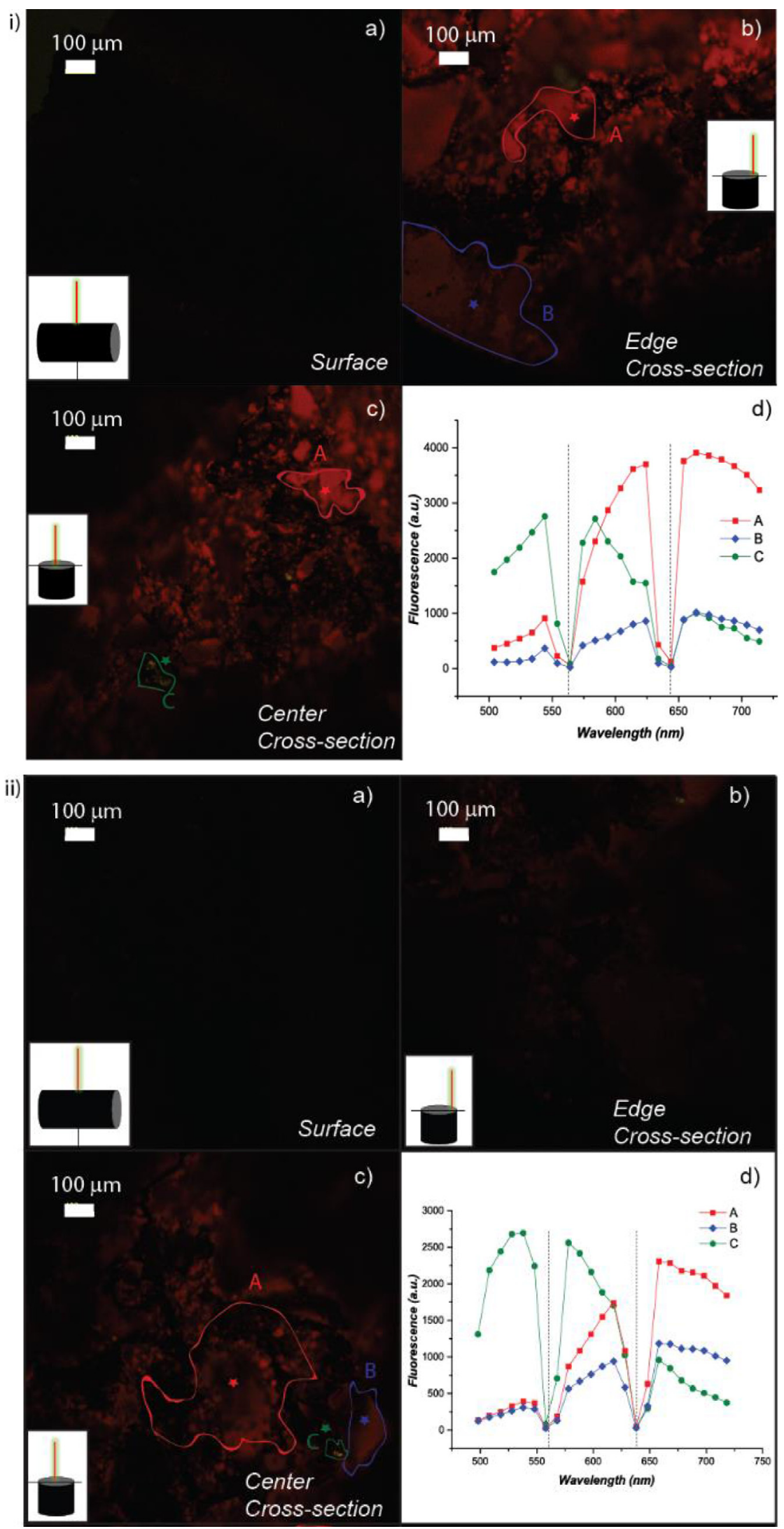

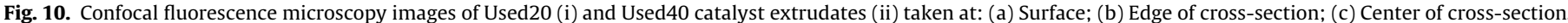

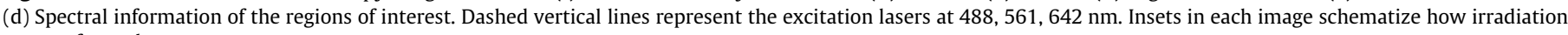
was performed. 


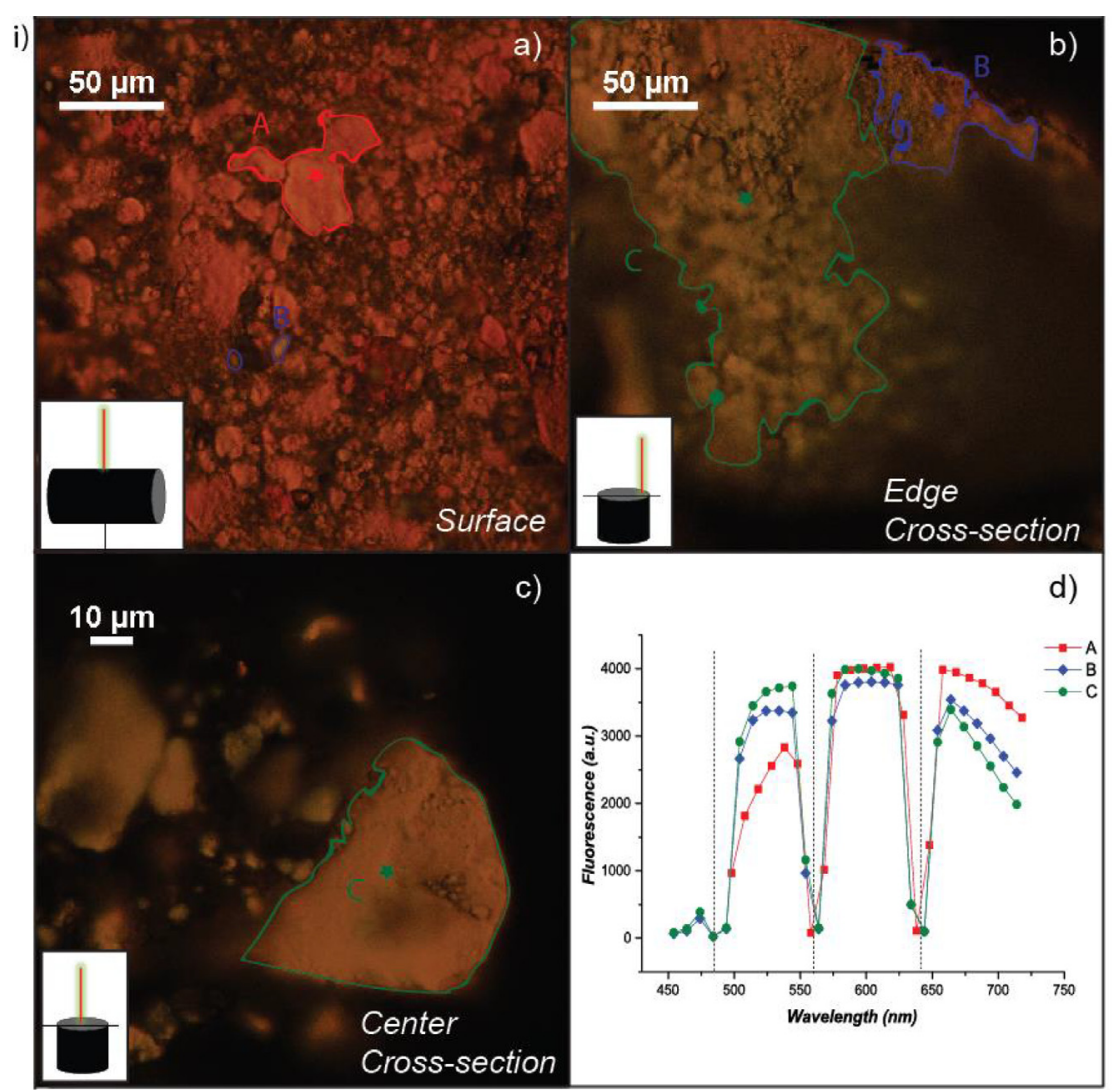

ii)

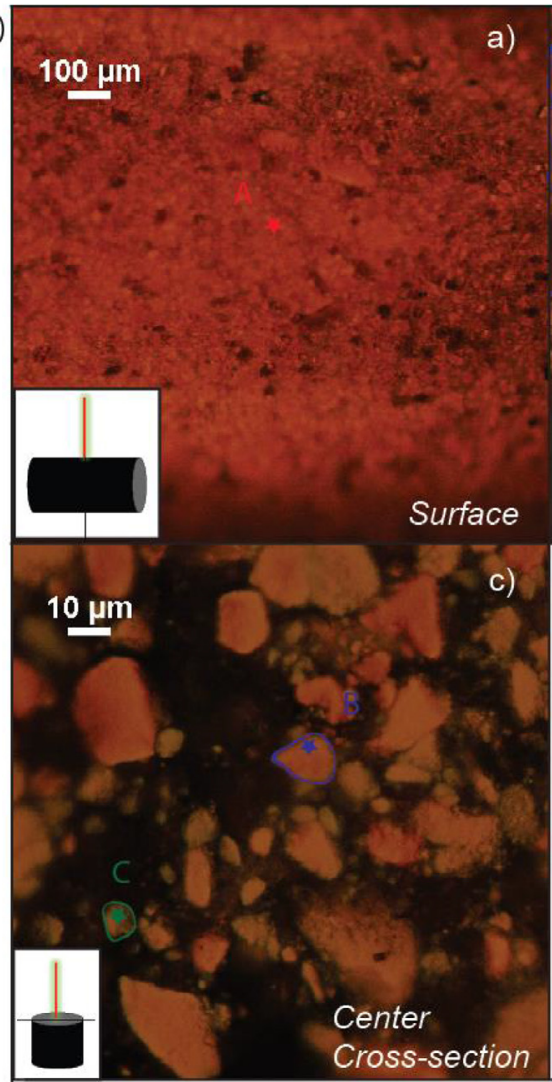

$100 \mu \mathrm{m}$

\section{)}


particular, they promote deoxygenation, decarboxylation, and decarbonylation of oxygenate components, as well as cracking, oligomerization, alkylation, isomerization, cyclization, and aromatization via a carbonium ion mechanism [56]. The observed decrease in the cracking and deoxygenation activity observed as a function of time-on-stream over the $\mathrm{ZrO}_{2} / \mathrm{n}$-ZSM-5-ATP catalyst further corroborates the blocking of the stronger acid sites. Characterization of spent HZSM-5 catalysts with different binders after catalytic pyrolysis of pine also showed that during the course of the upgrading reaction, the strong acid sites are preferentially deactivated as compared to the weak acid sites, with deactivation being likely caused by coke formation [21].

Confocal fluorescence microscopy analysis further revealed an egg-shell spatial distribution of the coke deposits (and their precursor molecules) within the catalyst extrudate that could suggest the existence of intra-particle mass and/or heat transfer limitations. Considering that the pores on macroparticle level are rather large (in-between meso- and macro-pores), mass transport phenomena can be ruled out. Differences in the spatial distribution of the zeolite and attapulgite across the extrudate, as well as heat transfer limitations due to the low thermal conductivity of both catalyst components, are more likely explanations for the observed egg-shell coke distribution. It is also plausible that the zeolite acid sites have a catalytic effect on the coke combustion reactions, facilitating the removal of carbon formed on the zeolite component of the catalyst. Not only the amount, but also the nature of the coke deposits changes from poly-aromatic ( $>\mathrm{C} 3$, H-poor coke) to naphthalene/anthracenes (H-rich coke) when moving from the edge to the center of the catalyst extrudate. The regions of softer coke (C) can be assigned to $\mathrm{ZrO}_{2}$ domains, in which the decreased amount of Brønsted acid sites leads to the formation of less polyaromatic coke [57]. These observations suggest that catalyst deactivation in the first $20 \mathrm{~min}$ of the CFP process can be explained in terms of acid site coverage in the pores, as well as pore blocking caused by softer coke deposits on the external surface covered mainly by $\mathrm{ZrO}_{2}$ domains.

Longer exposure to reaction conditions led to limited additional deposition of coke, occurring exclusively in the outer part of the zeolite. The textural properties of the used 20 and used 40 catalyst extrudates were indeed very similar. Any changes pertained only to loss of external surface area, also a result of the more accentuated agglomeration observed by TEM. The intensity differences between the $23.2(2 \theta)^{\circ}$ and $24.0(2 \theta)^{\circ}$ diffraction peaks in the XRD patterns, indicative of the incorporation of organics within the zeolite pores $[31,35]$, were very similar for the used 20 and used40 extrudates. The formation of external coke is in line with the acidity results, which showed that reduction in acidity from 20 to $40 \mathrm{~min}$ of reaction time is entirely due to the decrease of Lewis acid sites; Brønsted sites showed no further drop in abundance. Temperature programmed and isothermal oxidation analyses also revealed that the "extra" coke forming on the zeolite from 20 to 40 min reaction time was soft in nature and easily removable, given its high combustion rate.

The above observations strongly suggest that coking is the main reason for catalyst deactivation in the ex-situ CFP of biomass for the reaction time studied in this work. It should be mentioned that other modes of deactivation (such as dealumination, mineral poisoning, mechanical stability, etc.) could also become important after several hours time-on-stream. The majority of the coke build-up in the zeolite occurs early in the reaction, forming intra-porous coke on the strong Brønsted acid sites. These sites promote deep deoxygenation and cracking reactions, evidenced by the poly-aromatic nature of the deposited coke species. As the reaction further progresses, coke deposition slows down and occurs mainly on the external surface of the zeolite nanocrystals, leading to the formation of $\mathrm{H}$-richer softer coke on the $\mathrm{ZrO}_{2}$ domains of the catalyst material. This agrees well with the results of Cerqueira et al. [58], who showed that at short contact times deactivation is only due to acid site coverage, while at longer contact times deactivation is assigned to both site coverage and pore blocking, due to the increased coke amount and the deposition of coke in the outer part of the zeolite. Considering that in terms of pyrolysis products, $\mathrm{CO}$ production decreases with increasing time-on-stream, while the $\mathrm{CO}_{2}$ yield increases, it could be deduced that the strong acid sites of the zeolite mainly promote decarbonylation reactions, while the Lewis acid sites of the $\mathrm{ZrO}_{2}$ phase favor decarboxylation reactions that increase the deoxygenation selectivity of the catalyst.

Having identified coke deposition as the primary reason for deactivation and the nature, the location and amount of coke deposited after CFP established, the influence of catalyst regeneration parameters was assessed. The catalyst was readily regenerated via oxidation in air. The extent of the recovery of the initial features was found to depend on the regeneration temperature, with full recovery attained upon air oxidation at $500^{\circ} \mathrm{C}$. Combustion temperature of $400{ }^{\circ} \mathrm{C}$ was insufficient to completely remove all carbon deposits, as demonstrated by TPO, and in consequence also insufficient to fully recover the catalyst's acidic properties. This applies for both deactivated samples (after $20 \mathrm{~min}$ and $40 \mathrm{~min}$ reaction time), with the remnants being of poly-aromatic nature, i.e. $\mathrm{H}$ deficient coke species, as seen by confocal fluorescence microscopy. On the other hand, although regeneration at $600{ }^{\circ} \mathrm{C}$ suffices for removing both external and intra-porous coke, it resulted in partial zeolite dealumination, due to steaming effects upon coke combustion, as observed by the ${ }^{27} \mathrm{Al}$ (MQ) MAS NMR measurements. It should be noted that regeneration was performed under static conditions, which typically results in longer exposure of the catalyst to the produced water vapors. The limited dealumination could probably be avoided with regeneration in active flow that would quickly sweep the produced vapors and keep the $\mathrm{H}_{2} \mathrm{O}$ partial pressure at lower levels. The limited dealumination was reflected in the low recovery of the Brønsted acidity and some clustering/sintering of the zeolite ZSM- 5 crystals and the $\mathrm{ZrO}_{2}$ phase, as seen by TEM.

It is thus evident that optimum regeneration of the catalyst extrudates is achieved at $500{ }^{\circ} \mathrm{C}$, as all coke deposits can be removed with no detrimental effect on the catalyst structure, textural properties or type and strength of the acid sites.

\section{Conclusions}

Rapid catalyst deactivation in the catalytic fast pyrolysis (CFP) of biomass demands frequent regeneration with subsequent negative effects on the overall process costs. Understanding deactivation of real-life, shaped catalyst extrudates is essential for overcoming this challenge. In-depth characterization of deactivated zeolite $\mathrm{ZSM}-5$ based $\mathrm{ZrO}_{2}$-promoted extrudates, obtained after 20 and 40 min duration ex-situ CFP tests, revealed that deactivation is mostly related to coke that is deposited in an egg-shell spatial distribution manner on the catalyst extrudate rather than sintering or zeolite dealumination. The mode of catalyst deactivation changes with increasing time-on-stream. The majority of the coke deposits occurs early in the reaction and is of poly-aromatic nature, thereby leading to blockage of the strong Brønsted acid sites, responsible for catalyzing decarbonylation as well as deep cracking reactions. The rate of coke deposition progressively decreases with increasing time-on-stream. The nature of coke also changes to softer, external coke species that partially block the zeolite pores and the external surface. Optimum recovery of the initial catalyst properties and complete coke removal is achieved under air oxidation at $500{ }^{\circ} \mathrm{C}$, temperature suggested as optimal for catalyst regeneration. 


\section{Acknowledgements}

The work was conducted with support from the EU under the frame of the FP7 funded "CAScade deoxygenation process using tailored nanoCATalysts for the production of BiofuELs from lignocellullosic biomass - CASCATBEL" project (Grant agreement No. 604307). The authors want to acknowledge Dr. P. Pizarro and Dr. J.M. Coronado (all from IMDEA Energy) as well as Dr. A. Horvat (from SILKEM d.o.o.) for the provision of the fresh catalyst extrudates, and P.Á. Calvo Criado (from ENCE) for the provision of the biomass used as feedstock.

\section{Appendix A. Supplementary material}

Supplementary data to this article can be found online at https://doi.org/10.1016/j.jcat.2019.10.019.

\section{References}

[1] R.P. Anex, A. Aden, F.K. Kazi, J. Fortman, R.M. Swanson, M.M. Wright, J.A. Satrio R.C. Brown, D.E. Daugaard, A. Platon, G. Kothandaraman, D.D. Hsu, A. Dutta Techno-economic comparison of biomass-to-transportation fuels via pyrolysis, gasification, and biochemical pathways, Fuel 89 (2010) S29-S35.

[2] S. Wan, Y. Wang, A review on ex situ catalytic fast pyrolysis of biomass, Front. Chem. Sci. Eng. 8 (2014) 280-294.

[3] K.G. Kalogiannis, S.D. Stefanidis, A.A. Lappas, Catalyst deactivation, ash accumulation and bio-oil deoxygenation during ex situ catalytic fast pyrolysis of biomass in a cascade thermal-catalytic reactor system, Fuel Process. Technol. 186 (2019) 99-109.

[4] A.A. Lappas, K.G. Kalogiannis, E.F. Iliopoulou, K.S. Triantafyllidis, S.D. Stefanidis, Catalytic pyrolysis of biomass for transportation fuels, WIREs Energy Environ. 1 (2012) 285-297.

[5] M. Guisnet, P. Magnoux, D. Martin, Roles of acidity and pore structure in the deactivation of zeolites by carbonaceous deposits, Stud. Surf. Sci. Catal. 111 (1997) $1-19$.

[6] A.R. Stanton, K. Iisa, C. Mukarakate, M.R. Nimlos, Role of biopolymers in the deactivation of ZSM-5 during catalytic fats pyrolysis of biomass, ACS Sustain. Chem. Eng. 6 (2018) 10030-10038.

[7] M.M. Yung, A.R. Stanton, K. Iisa, R.S. French, K.A. Orton, K.A. Magrini-Bair, Multi-scale evaluation of catalytic upgrading of biomass pyrolysis vapors on Ni- and Ga-modified ZSM-5, Energy Fuels 30 (2016) 9471-9479.

[8] K. Iisa, R.J. French, K.A. Orton, M.M. Yung, D.K. Johnson, J. te Dam, M.J. Watson, M.R. Nimlos, In situ and ex situ catalytic pyrolysis of pine in a bench-scale fluidized bed reactor system, Energy Fuels 30 (2016) 2144-2157.

[9] M.D. Argyle, C.H. Bartholomew, Heterogeneous catalyst deactivation and regeneration: A review, Catalysts 5 (2015) 145-269.

[10] B.W. Weckhuysen, E.T.C. Vogt, Fluid catalytic cracking: recent developments on the grand old lady of zeolite catalysts, Chem. Soc. Rev. 44 (2015) 7342 7370 .

[11] S. Vitolo, B. Bresci, M. Seggiani, M.G. Gallo, Catalytic upgrading of pyrolytic oils over HZSM-5 zeolite: behaviour of the catalyst when used in repeated upgrading-regenerating cycles, Fuel 80 (2001) 17-26.

[12] Z. Ma, J.A. van Bokhoven, Deactivation and regeneration of H-USY during lignin catalytic fast pyrolysis, ChemCatChem 4 (2012) 2036-2044.

[13] S. Wan, C. Waters, A. Stevens, A. Gumidyala, R. Jentoft, L. Lobban, D. Resasco, R. Mallinson, S. Crossley, Decoupling HZSM-5 catalyst activity from deactivation during upgrading of pyrolysis oil vapors, ChemSusChem 8 (2015) 552-559.

[14] M.M. Yung A.K. Starace, M.B. Griffin, J.D. Wells, R.E. Patalano, K.R. Smith, J.A. Schaidle, Restoring ZSM-5 performance for catalytic fast pyrolysis of biomass: Effect of regeneration temperature, Catal. Today 323 (2019) 76-85.

[15] M. Ibáñez, B. Valle, J. Bilbao, A.G. Gayubo, P. Castaño, Effect of operating conditions on the coke nature and HZSM-5 catalysts deactivation in the transformation of crude bio-oil into hydrocarbons, Catal. Today 195 (2012) 106-113.

[16] B. Valle, P. Castaño, M. Olazar, J. Bilbao, A.G. Gayubo, Deactivating species in the transformation of crude bio-oil with methanol into hydrocarbons on a HZSM-5 catalyst, J. Catal. 285 (2012) 304-314.

[17] C. Mukarakate, X. Zhang, A.R. Stanton, D.J. Robichaud, P.N. Ciesielski, K. Malhotra, B.S. Donohoe, E. Gjersing, R.J. Evans, D.S. Heroux, R. Richards, K. Iisa, M.R. Nimlos, Real-time monitoring of the deactivation of HZSM-5 during upgrading of pine pyrolysis vapors, Green Chem. 16 (2014) 1444-1461.

[18] Y.-S. Chou, M.-H. Huang, N.-Y. Hsu, K.-T. Jeng, R.-Y. Lee, S.-C. Yen, Development of ring-shape supported catalyst for steam reforming of natural gas in small SOFC systems, Int. J. Hydrogen Energ. 41 (2016) 12953-12961.

[19] L.F. Bobadilla, A. Álvarez, M.I. Domínguez, F. Romero-Sarria, M.A. Centeno, M. Montes, J.A. Odriozola, Influence of the shape of Ni catalysts in the glycerol steam reforming, Appl. Catal. B-Environ. 123-124 (2012) 379-390.
[20] M. Ibáñez, M. Gamero, J. Ruiz-Martínez, B.M. Weckhuysen, A.T. Aguayo, J. Bilbao, P. Castaño, Simultaneous coking and dealumination of zeolite H-ZSM-5 during the transformation of chloromethane into olefins, Catal. Sci. Technol. 6 (2016) 296-306.

[21] K. Iisa, R.J. French, K.A. Orton, S. Budhi, C. Mukarakate, A.R. Stanton, M.M. Yung, M.R. Nimlos, Catalytic pyrolysis of pine over HZSM-5 with different binders, Top. Catal. 59 (2016) 94-108.

[22] G.J. Hutchings, R.G. Copperthwaite, T. Themistocleous, G.A. Foulds, A.S Bielovitch, B.J. Loots, G. Nowitz, P. Van Eck, A comparative study of reactivation of zeolite $\mathrm{Y}$ using oxygen and ozone/oxygen mixtures, Appl. Catal. 34 (1987) 153-161.

[23] G.T. Whiting, N. Nikolopoulos, I. Nikolopoulos, A.D. Chowdhury, B.M. Weckhuysen, Visualizing pore architecture and molecular transport boundaries in catalyst bodies with fluorescent nanoprobes, Nat. Chem. 11 (2018) 23-31.

[24] H. Hernado, A.M. Hernandez-Gimenez, C. Ochoa-Hernadez, P.C.A. Bruijinincx, K. Houben, M. Baldus, P. Pizarro, J. Coronado, J. Fermoso, J. Cejka, B.M. Weckhuysen, D.P. Seranno, Engineering the acidity and accessibility of the zeolite ZSM-5 for efficient bio-iol upgrading in catalytic pyrolysis of lignocellulose, Green Chem. 20 (2018) 3499-3511.

[25] H. Hernando, C. Ochoa-Hernandez, M. Shamzhy, I. Moreno, J. Fermoso, J. Coronado, J. Cejka, D.P. Seranno, The crucial role of clay binders in the performance of ZSM-5 based materials for biomass catalytic pyrolysis, Catal. Sci. Technol. 9 (2019) 789-802.

[26] A. Travert, A. Vimont, A. Sahibed-Dine, M. Daturi, J.C. Lavalley, Use of pyridine $\mathrm{CH}(\mathrm{D})$ vinrations for the study of Lewis acidity of metal oxides, Appl. Catal. AGen. 307 (2006) 98-107.

[27] J.A. Lercher, A. Jentys, Chapter 13 Infrared and raman spectroscopy for characterizing zeolites, Stud. Surf. Sci. Catal. 168 (2007) 435-476.

[28] C.A. Emeis, Determination of integrated molar extinction coefficients for infrared absorption bands of pyridine adsorbed on solid acid catalysts, J. Catal. 141 (1993) 347-354.

[29] A.G. Gayubo, A.T. Aguayo, A. Atutxa, R. Prieto, J. Bilbao, Deactivation of ZSM-5 in upgrading of aq. bio-oil, Energy Fuels 18 (2004) 1640-1647.

[30] S. Cheng, L. Wei, X. Zhao, J. Julson, Application, deactivation, and regeneration of heterogeneous catalysts in bio-oil upgrading review of deactivation and regeneration of pyrolysis catalysts, Catalysts 6 (2016) 195-219.

[31] E.L. Wu, S.L. Lawton, D.H. Olson, A.C. Rohrman, G.T. Kokotailo, ZSM-5-type materials. Factors affecting crystal symmetry, J. Phys. Chem. 83 (1979) 27772781.

[32] T. Armaroli, L.J. Simon, M. Digne, T. Montanari, M. Bevilacqua, V. Valtchev, J. Patarin, G. Busca, Effects of crystal size and Si/Al ratio on the surface properties of H-ZSM-5 zeolites, App. Catal. A-Gen. 306 (2006) 78-84.

[33] R. Fricke, H. Kosslick, V. Tuan, I. Grohmann, W. Pilz, W. Storek, G. Walther, Study on the isomorphous substitution of silicon by tetravalent elements ( $\mathrm{Zr}$, $\mathrm{Ge}, \mathrm{Ti}$ ) in the framework of MFI type zeolites, Zeolites Surf. Sci. Catal. 83 (1993) $57-66$.

[34] J.P. Li, S.H. Meng, J.C. Han, X.H. Zhang, Valence electron structure and properties of the $\mathrm{ZrO}_{2}$, Sci. China Ser. E-Tech. Sci. 51 (2008) 1858-1866.

[35] A.G. Alvarez, H. Viturro, R.D. Bonetto, Structural changes on deactivation of ZSM5. A study by X-ray powder diffraction, Mater. Chem. Phys. 32 (1992) 135-140.

[36] Y. Fan, Y. Cai, X. Li, H. Yin, J. Xia, Coking characteristics and deactivation mechanism of the HZSM-5 zeolite employed in the upgrading of biomassderived vapors, J. Ind. Eng. Chem. 46 (2017) 139-149.

[37] J. Hoekstra, A.M. Beale, F. Soulimani, M. Versluijs-Helder, D. Van De Kleut, J.M. Koelewijn, W. Geus, L.W. Jenneskens, The effect of iron catalyzed graphitization on the textural properties of carbonized cellulose: Magnetically separable graphitic carbon bodies for catalysis and remediation, Carbon 107 (2016) 248-260.

[38] C. Cobzaru, S. Oprea, E. Dumitriu, V. Hulea, Gas phase aldol condensation of lower aldehydes over clinoptilolite rich natural zeolites, Appl. Catal. A-Gen. 351 (2008) 253-258.

[39] A. Samoson, E. Lippmaa, G. Engelhardt, U. Lohse, H.-G. Jerschkewitz, Quantitative high-resolution 27Al NMR: tetrahedral non-framework aluminium in hydrothermally treated zeolites, Chem. Phys. Lett. 134 (1987) 589-592.

[40] L. Rodriguez-Gonzalez, F. Hermes, M. Bertmer, E. Rodriguez-Castellon, A. Jimenez-Lopez, U. Simon, The acid properties of H-ZSM-5 as studied by $\mathrm{NH}_{3}$ TPD and ${ }^{27}$ Al-MAS-NMR spectroscopy, App. Catal. A-Gen. 328 (2007) 174-182.

[41] J.L. Bonardet, M.C. Barrage, J. Fraissard, Use of NMR techniques for studying deactivation of zeolites by coking, J. Mol. Catal. A-Chem. 96 (1995) 123-143.

[42] A. Devaraj, M. Vijayakumar, J. Bao, M.F. Guo, M.A. Derewinski, Z. Xu, M.J. Gray, S. Prodinger, K.K. Ramasamy, Discerning the location and nature of coke deposition from surface to bulk of spent zeolite catalysts, Sci. Rep. 6 (2016) 37586-37597.

[43] H. Yang, A. Tang, J. Ouyang, M. Li, S. Mann, From natural attapulgite to mesoporous materials: methodology, characterization and structural evolution, J. Phys. Chem. B 114 (2010) 2390-2398.

[44] H. Birgersson, L. Eriksson, M. Boutonnet, S.G. Järås, Thermal gas treatment to regenerate spent automotive three-way exhaust gas catalysts (TWC), Appl. Catal. B-Environ. 54 (2004) 193-200.

[45] J. Zhang, X. Liu, Photocatalytic hydrogen production from water under visible light irradiation using a dye-sensitized attapulgite nanocrystal photocatalyst, Phys. Chem. Chem. Phys 16 (2014) 8655-8660. 
[46] W.F. Bradley, The structural scheme of attapulgite, Am. Mineral. 25 (1940) 405-410.

[47] O. Sánchez-Galofré, Y. Segura, J. Pérez-Ramírez, Deactivation and regeneration of iron-containing MFI zeolites in propane oxidative dehydrogenation by $\mathrm{N}_{2} \mathrm{O}$, J. Catal. 249 (2007) 123-133.

[48] G. Elordi, M. Olazar, G. Lopez, P. Castaño, J. Bilbao, Role of pore structure in the deactivation of zeolites (HZSM-5, H $\beta$ and $\mathrm{HY}$ ) by coke in the pyrolysis of polyethylene in a conical spouted bed reactor, App. Catal. B-Environ. 102 (2011) 224-231.

[49] H. Zhang, S. Shao, R. Xiao, D. Shen, J. Zeng, Characterization of coke deposition in the catalytic fast pyrolysis of biomass derivates, Energ. Fuel. 28 (2014) 5257.

[50] S. Dimovski, A. Nikitin, H. Ye, Y. Gogotsi, Synthesis of graphite by chlorination of iron carbide at moderate temperatures, J. Mat. Chem. 14 (2004) 238-243.

[51] W.-H. Chen, H.-H. Ko, A. Sakthivel, S.-J. Huang, S.-H. Liu, A.-Y. Lo, T.-C. Tsai, S.-B Liu, A solid-state NMR, FT-IR and TPD study on acid properties of sulfated and metal-promoted zirconia: Influence of promoter and sulfation treatment, Catal. Today 116 (2006) 111-120.

[52] A.N. Parvulescu, D. Mores, E. Stavitski, C.M. Teodorescu, P.C.A. Bruijnincx, R.J. M.K. Gebbink, B.M. Weckhuysen, Chemical imaging of catalyst deactivation during the conversion of renewables at the single particle level: Etherification of biomass-based polyols with alkenes over H-Beta zeolites, J. Am. Chem. Soc. 132 (2010) 10429-10439.

[53] E.C. Nordvang, E. Borodina, J. Ruiz-Martínez, R. Fehrmann, B.M. Weckhuysen, Effects of coke deposits on the catalytic performance of large zeolite H-ZSM-5 crystals during alcohol-to-hydrocarbon reactions as investigated by a combination of optical spectroscopy and microscopy, Chem. Eur. J. 21 (2015) $17324-17335$.

[54] H. Benesi, B. Winquist, Surface acidity of solid catalysts, Adv. Catal. 27 (1979) 97-182.

[55] P. Magnoux, P. Cartraud, S. Mignard, M. Guisnet, Coking aging, and regeneration of zeolites: II. Deactivation of HY zeolite during n-heptane cracking, J. Catal. 106 (1987) 235-241.

56] C. Liu, H. Wang, A.M. Karim, J. Suna, Y. Wang, Catalytic fast pyrolysis of lignocellulosic biomass, Chem. Soc. Rev 43 (22) (2014) 7594-7623.

[57] B. Delmon, G.F. Froment, Catalyst deactivation, Stud. Surf. Sci. Catal. 34 (1987).

[58] H.S. Cerqueira, P. Magnoux, D. Martin, M. Guisnet, Effect of contact time on the nature and location of coke during methylcyclohexane transformation over a USHY zeolite, Stud. Surf. Sci. Catal. 126 (1999) 105-112. 